\title{
Systematic Review on Evaluation of Health Impact Assessments in Iran: Evolution, Studies and Areas for Improvement
}

\author{
Edris Hoseinzadeh ${ }^{1}$, Bahare Mirza Hedayat ${ }^{2 *}$, Sedigheh Karimpour Roshan ${ }^{2}$ \\ 1. Young Researchers and Elite Club, Hamedan Branch, Islamic Azad University, Hamedan, Iran \\ 2. Department of Environmental Health Engineering, Faculty of Health, Alborz University of Medical sciences, Karaj, \\ Iran
}

*E-mail: baharhedayat21@gmail.com

Received: 24 Dec 2016 ; Accepted: 2 May 2017

\begin{abstract}
Background \& Objective: Health impact assessment (HIA) is used for identification activities and policies that have significant effects on human health. In addition to large projects and plans, it could be contain different fields. The aim of present study was to do a systematic review on available performed HIAs in Iran to express position and pathway which HIA has been passed.

Methods: This study is a systematic review which tried to collect all information from scientific databases. We used both English and Persian databases to find any document.

Results: Total obtained items were 181 documents which related items with our topics were 95 . The number of items in air pollution, occupational cases, petrochemical, noise pollution, urban subjects, health, principles of HIA, and other fields were 48, 7, 2, 2, 9, 3,14 and10, respectively.

Conclusion: Health Impact Assessment (HIA) has been required for large development projects by the fifth development plan, however, there is a need to HIA by another fields such as air pollution and urban subjects as they have effects on human health. Presenting such assessment before presentation national health standards requirement of Iran indicates this fact. Thus, we expect from politicians and decision makers to address these issues and apply HIA by other fields alongside assessment of national development projects and plans. By doing so, we can bridge the gap between knowledge and action which may result in health promotion in the society.
\end{abstract}

Keywords: Health Impact Assessment, Development Plans, Iran, Systematic Review 


\title{
مرور سيستماتيك بر روى بررسى جايگاه ارزيايى اثرات بر سلامت در ايران: تكامل، تحقيقات و زمينههاى بهبود آن
}

\author{
ادريس حسينزاده'، بهاره ميرزاهدايت"،: صديقه كريميور روشن'

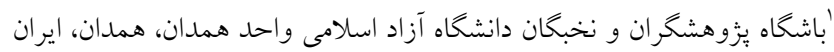

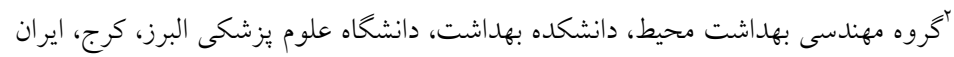

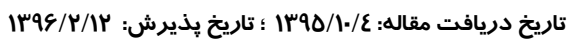

\section{جكيده}

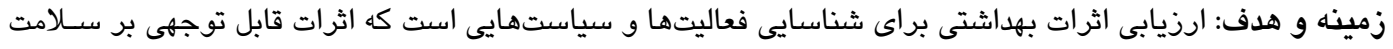

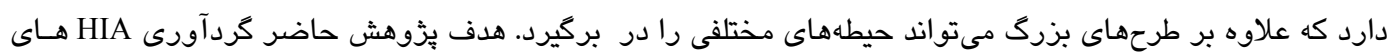

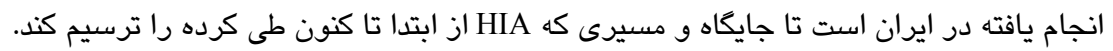

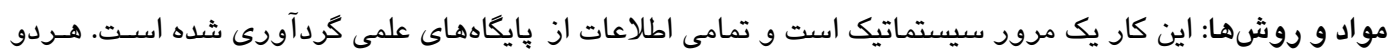

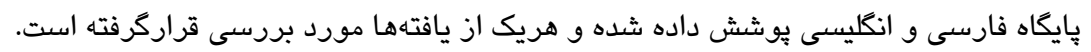

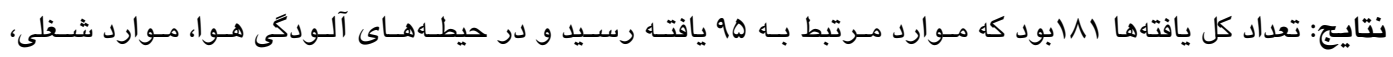

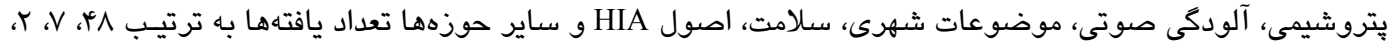

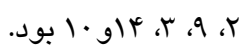

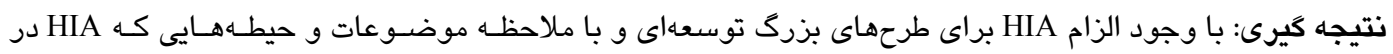

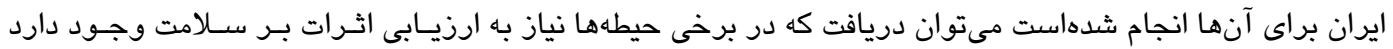

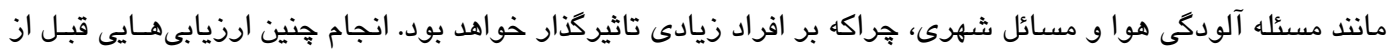

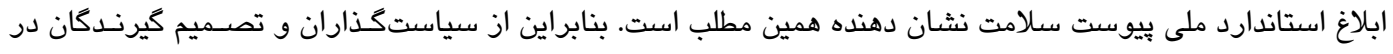

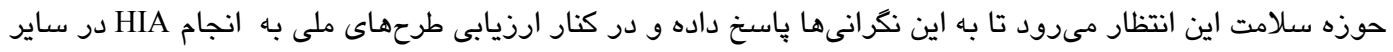

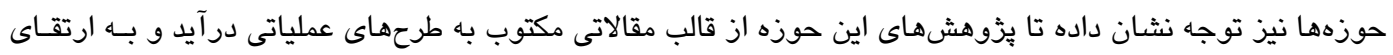
هرجه بيشتر سلامت در جامعه بيانجامد. 
مى گيرد. از آنجا كه سياستها و قوانين و برنامهاى هر

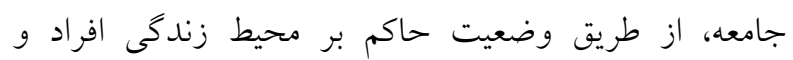

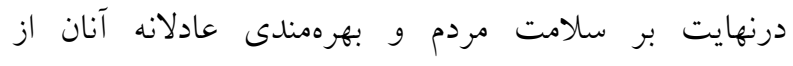

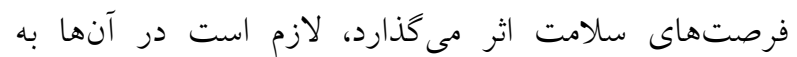

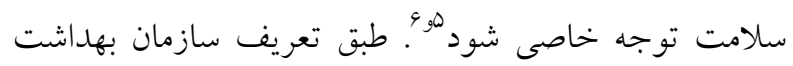

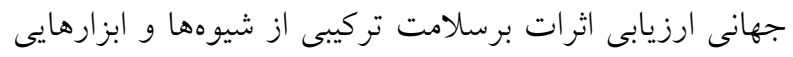

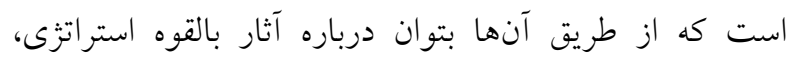
سياست، برنامه يا يروزه برروى سلامتى هر جمعيت و توزيع

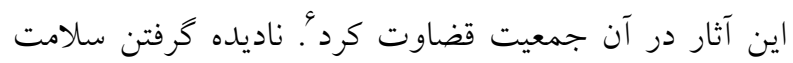
دار و همجنين افزايش تاكيد بر مولفههاى اجتماعى موثر

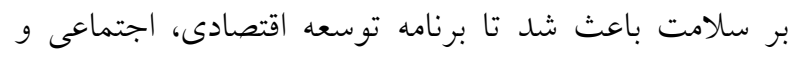

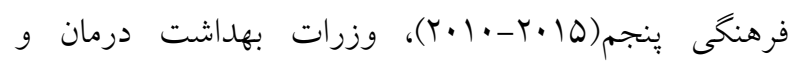

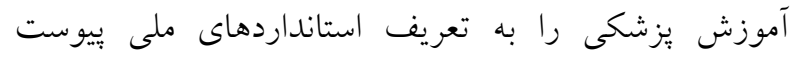

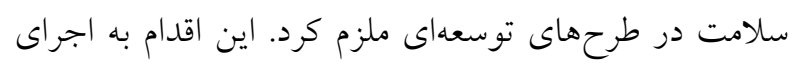

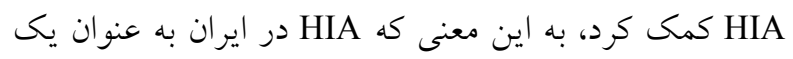

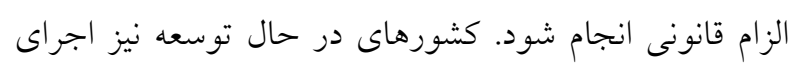

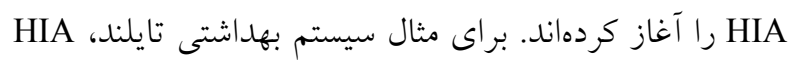

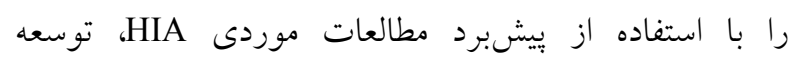

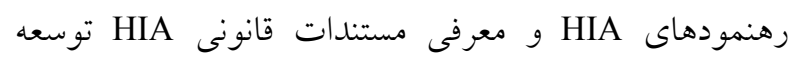
دادهاست. با اينحال تاكنون در ايران هيج تحقيقى كه بر نحوه تطابق HIA با شرايط ايران متمركز باشد انجام نشدهاست.

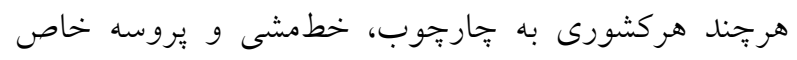

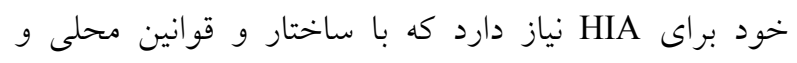

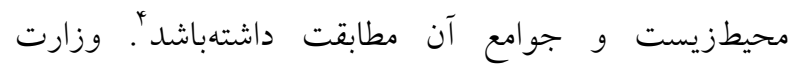

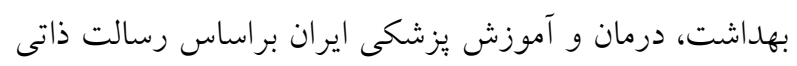

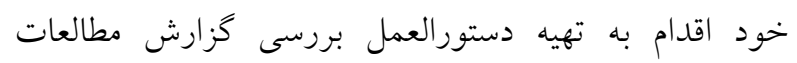

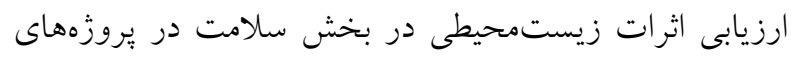

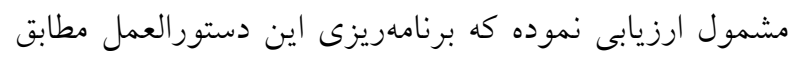

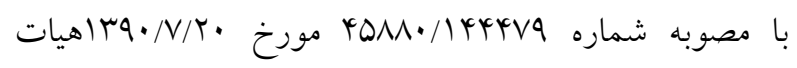

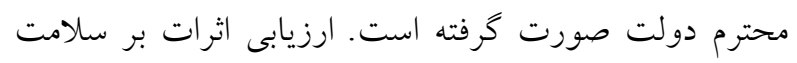

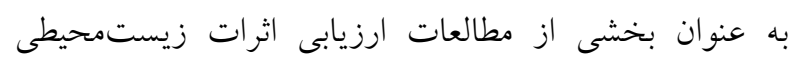

\section{مقدمه}

اغلب كشورهاى دنيا بيش از اتخاذ تصميم نهايى، اثرات يروزههاى توسعهاى بر سلامت را ارزيابى مى كنند.'. فرآيند تهيه گزارش ارزيابى اثرات زيستمحيطى(EIA) براى اولين بار در سال 1999 ميلادى با وضع قانون سياست زيستمحيطى ملى در آمريكا (NEPA) جنبه رسمى به خودگرفت. بعد از كنفرانس استكهلم در سال 9VYاميلادى بسيارى از كشورها خود را موظف به انجام مطالعات EIA قبل

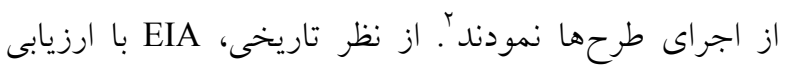
يروزههاى مهم زيستمحيطى بيوند نزديكى دارد. از آنجايى كه فعاليت ارزيابى اثرات در ارزيابى زيستمحيطى استراتزيكى و ديخر انواع ارزيابىهاى اثرات، توسعه يافتهاست اما اغلب به اثرات روى سلامت بشر توجهى نمىشودّاّ انجام

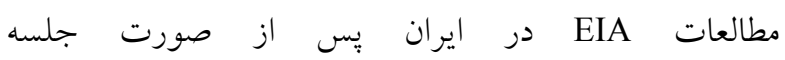
مورخ سץ//Tr/I شوراى عالى حفاظت محيطزيست كشور الزامى گرديد. بر اين اساس مجريان بروزههاى بزرگ ملزم

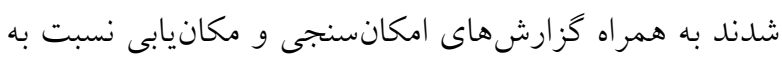
تهيه گزارش جامع ارزيابى اثرات زيستمحيطى نيروزهها اقدام نمايند.ّ. اما ارزيابى اثرات بر سلامت در ارزيابى هاى اثرات زيستمحيطى بهطور دقيق انجام نشد و فقط در برخى از يروزههاى مربوط به آلودگى هوا، تصفيهخانه فاضلاب و بروزههاى صنعتى با استغاده از دستور العملهاى EHIA انجام

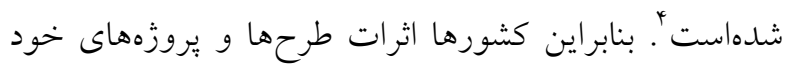
را بر سلامت در قالب يك ارزيابى مجزا كه همان ارزيابى

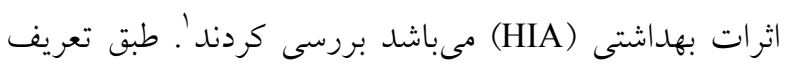
سازمان بهاشت جهانى، سلامتى تحت تأثير دامنهاى از عوامل

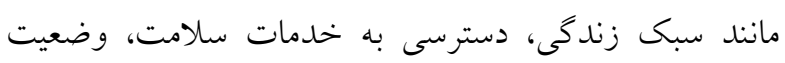
اقتصادى، اجتماعى و ... قراردارد. در دهههاى •191 و •199، ارزيابى اثرات سلامت در جند نقطه از جهان مطرح شد. اين ارزيابى اشاره مىكرد كه سلامتى و رفاه، به طور وسيعى به وسيله عواملى خارج از بخش سلامت تحت تأثير قرار 
ذكر اين نكته ضرورى است كه در ارزيابى اثرات زيست

محيطى(EIA) كه در ايران قدمتى بيشتر ازHIA دارد نيز تا

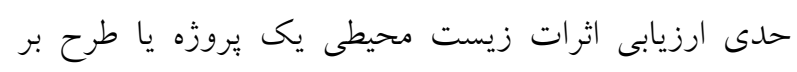
سلامت انسان مورد بررسى قرار مى گيرد. اما به دليل اينكه بعد

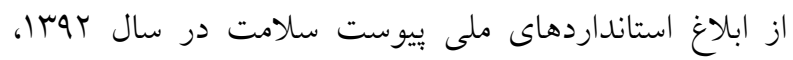
انجام ارزيابى اثرات بهداشتى براى طرحهاى بزرى توسعهاى الزامى شد و HIA به عنوان يك بخش مجزا در نظر كرفتهشد

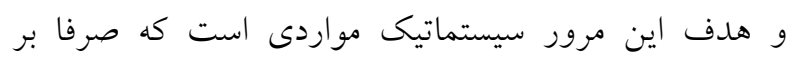
ارزيابى اثرات بهداشتى برداخته، در نتيجه از ذكر منابعى كه به ارزيابى اثرات زيست محيطى مى بردازد خوددارى كرديله است. همجنين در اين مقاله از يافتهايى كه قبل از بوبا به ارزيابى اثرات بهداشتى برداخته نيز استفاده شده و در كل سعى شدهاست تا تمامى يافتههاى مرتبط با ارزيابى اثرات

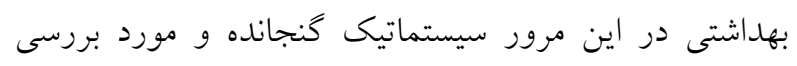
قرار گيرد. يايخاه دادههاى داخلى سيويليكا، سامانه دانش گستر بركت، Sid magiran و پِايخاه دادههاى بين المللى Google، science ، Embase، web of science ،Google scholar PubMed و Scopus ، BioMed ، direct كلمات كليدى براى جستجوى فارسى شامل ارزيابى اثرات

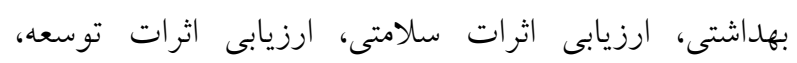
health سياست هاى سلامت و براى جستجوى انخليسى شامل health improvement health policy impact assessment Iran بود كه در انتها كلمه decision making \& HIA plans نيز درج شد. براى انتخاب يافتهاى مرتبط در اين مرور سيستماتيك از فلوجارتى كه در بيانيه PRISMA منتشر شده بيه

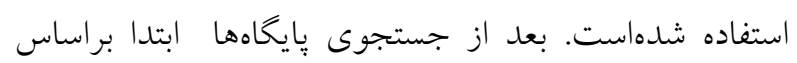

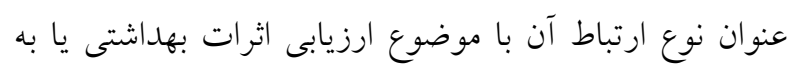

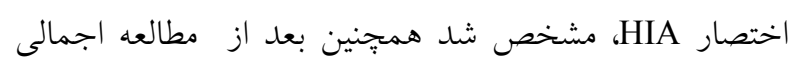

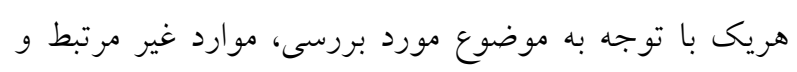

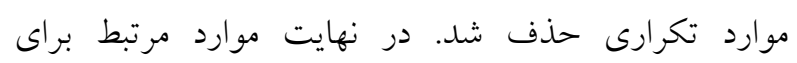
استخراج دادهها مورد تحليل قرار كرفت.
محسوب مىشود كه مىبايست تحت نظارت و هماهنكى

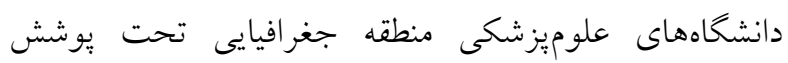

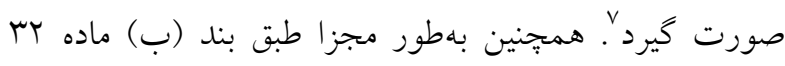
قانون برنامه ينجم توسعه، شوراى عالى سلامت و امنيت

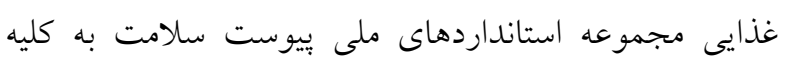
دستخاههاى اجرايى ابلاغ شد. طبق اين ابلاغيه تمامى طرحهاى بزرى توسعهاى ملزم به انجام HIA مىباشند. ارزيابى اثرات سلامتى براى شناسايى آن دسته از فعاليتها و سياستهايى است كه اثرات قابلتوجهى بر سلامت عموم دارند تا اثرات زيانآ آور بر سلامت را كاهش داده و اثرات مفيد را افزايش دهد. اثرات بالقوه سلامتى در يك طرح بيشنهادى،

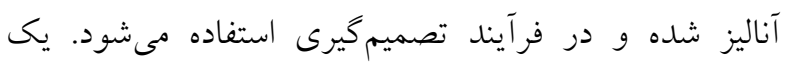
ارزيابى اثرات سلامتى براساس مدلهاى سلامتى است كه

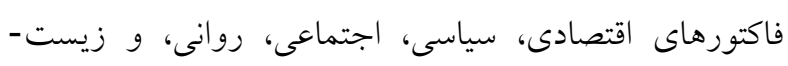

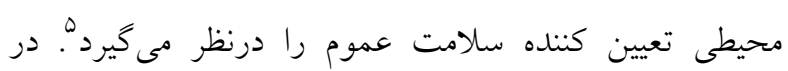
مطالعه يِيشرو يزوهشها و كزارشات در زمينه ارزيابى اثرات بهداشتى كه صرفا در ايران انجام شده، در قالب مرورى سيستماتيك كردآورى شدهاست تا اقدامات انجامشده و ور مسيرى كه HIA تاكنون طى كرده ترسيم كند. اين بزوهش با توجه به اينكه HIA در سالهاى اخير جايخاه ويزهاى يافتهاست،اهميت بيدا مى كند. و مىتواند مورد توجه مسئولان اين لونه

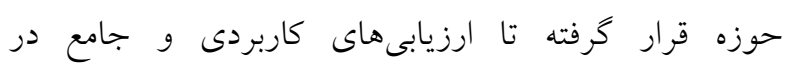
حوزههاى مختلف انجامشده و از قالب تحقيقات و مقالات كتبى به يروزههاى كاربردى و عملياتى بيانجامد.

\section{مواد و روشها}

اين بُزوهش مرورى سيستماتيك از ارزيابىهاى اثرات بهداشتى انجامشده در ايران است. درنتيجه جستجو در بين منابع مرتبط به ايران انجام شدهاست. يافتهها شامل مقالات به به به بهات

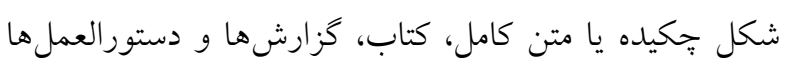

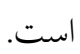


شدهاند. ش个 يافته مربوط به ارزيابى اثرات بهداشتى در حوزه

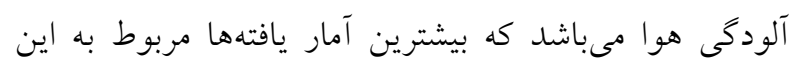

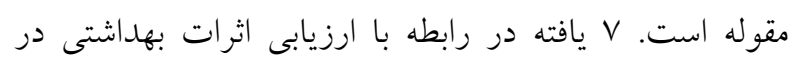

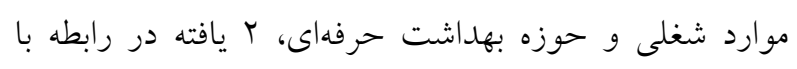

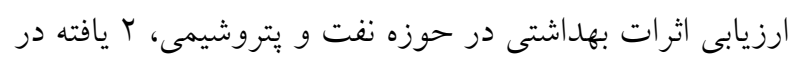
رابطه با ارزيابى اثرات بهداشتى در حوزه آلودكى صوتى، آنى 9

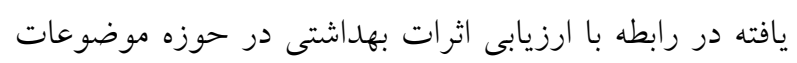

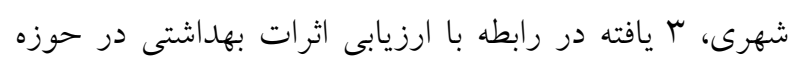

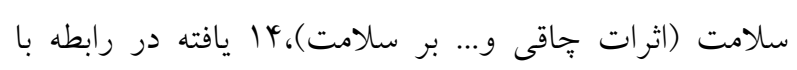

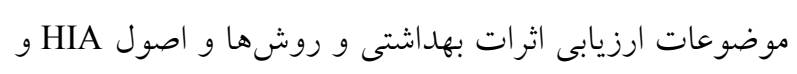
•ايافته نيز در رابطه ارزيابى اثرات بهداشتى در ساير حوزهها. مىباشد. بر مبناى استراتزى جستجوى تعريف شده تعداد

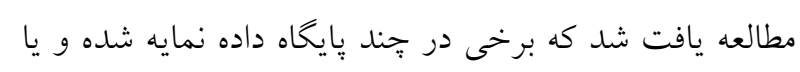
بعضى مقالات به صورت فارسى و هم انخليسى در دو پايخاه

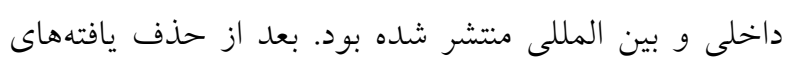

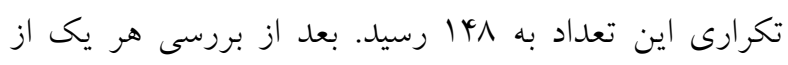

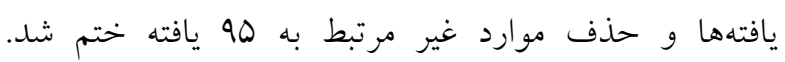

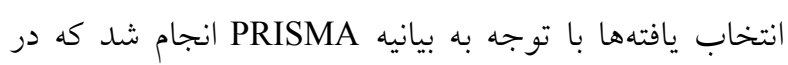

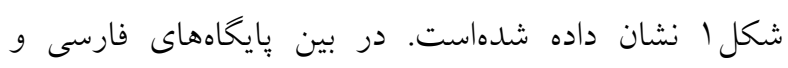

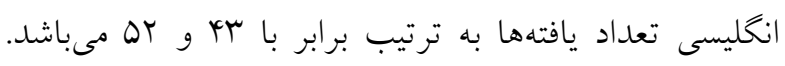

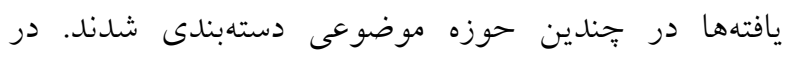

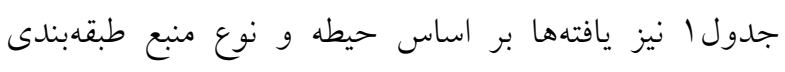

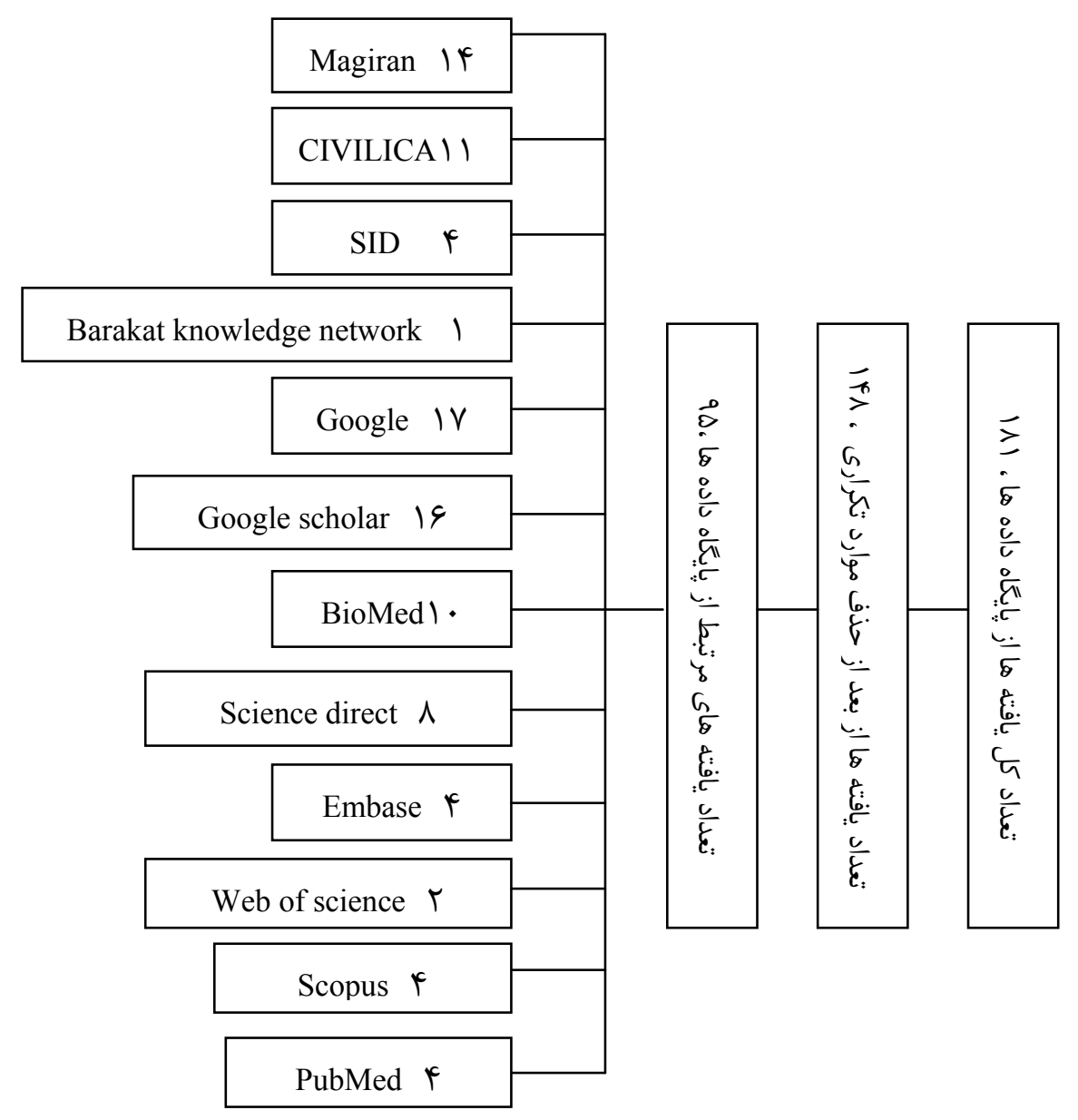

شكلا: نتايج دستهبندى و انتخاب يافتهها بر اساس بايڤاه داده 
مرور سيستماتيك بر روى بررسى جايكاه ارزيابى اثرات بر سلامت در ايران: تكامل، تحقيقات و زمينهاى بهبود آن

جدولا: نتايج دسته بندى يافتها بر اساس نوع منبع و حيطه مورد مطالعه

\begin{tabular}{|c|c|c|c|c|c|c|c|}
\hline \multirow{2}{*}{ مجموع كل } & \multirow{2}{*}{ كزارش } & \multirow{2}{*}{ دستور العمل } & \multirow{2}{*}{ كتاب } & \multirow{2}{*}{ جكيده پايان نامه } & \multicolumn{2}{|c|}{ 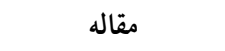 } & \multirow{2}{*}{ نوع منبع } \\
\hline & & & & & جكيده & متن كامل & \\
\hline rA & - & - & - & 1 & 9 & r & آلودكى هوا \\
\hline v & - & - & - & - & 1 & 4 & موارد شغلى و حوزه بهداشت حرفهاى \\
\hline r & - & - & 1 & - & 1 & - & نفت و پيتروشيمى \\
\hline r & - & - & - & - & - & r & آلودخى صوتى \\
\hline 9 & - & - & - & 1 & 1 & v & موضوعات شهرى \\
\hline r & - & - & - & - & - & r & حوزه سلامت \\
\hline 14 & - & r & - & - & r & 9 & روشها و اصول HIA \\
\hline $1 \cdot$ & r & 1 & - & - & 0 & r & ساير حوزهها \\
\hline
\end{tabular}

استفاده شدهاست. مـدل Air Q يكسى از معتبرتـرين روشهـا

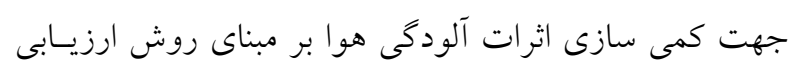

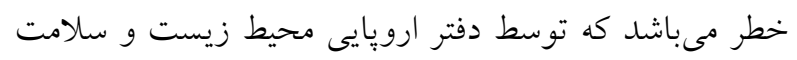

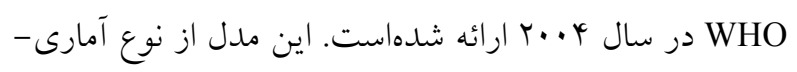

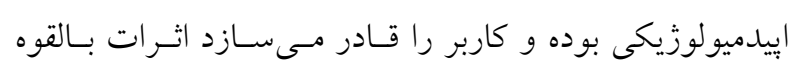

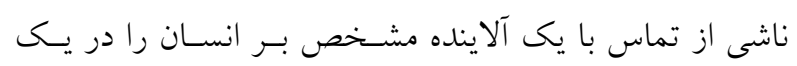

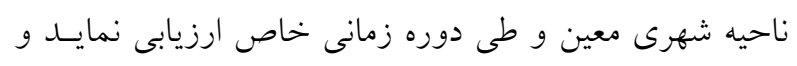

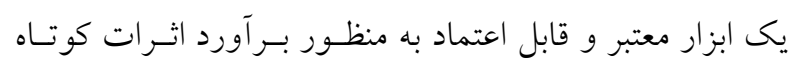

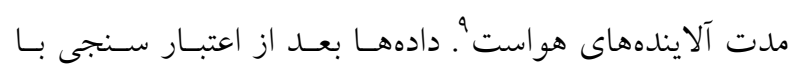

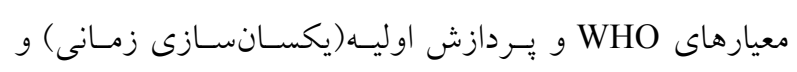

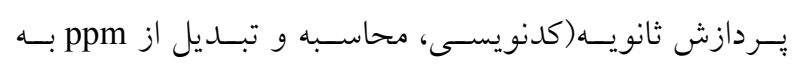
Mg/m³ و اصلاح شر ايط دما و فشار بــر اسـاس معادلـه كـاز كامل) در محيط اكسل به دادههاى مورد استفاده در نـرم افز فرار

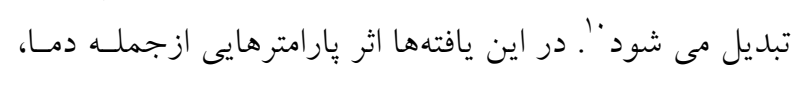

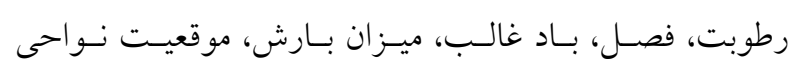

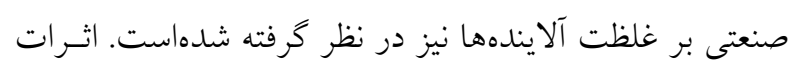

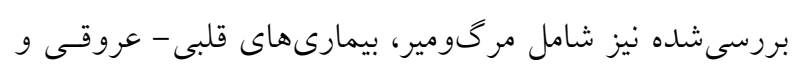

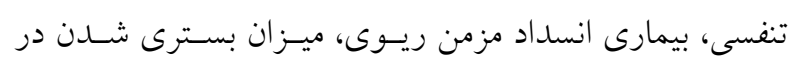

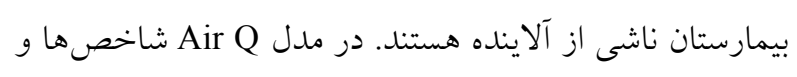

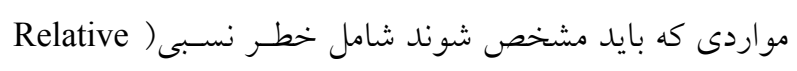

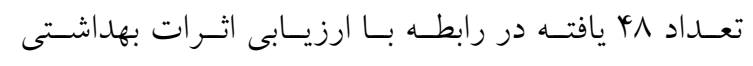

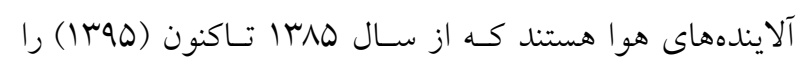

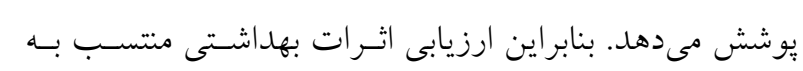

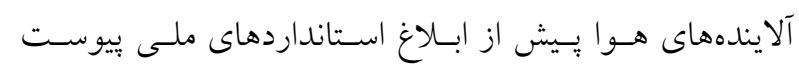

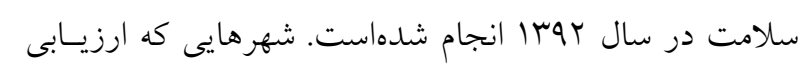

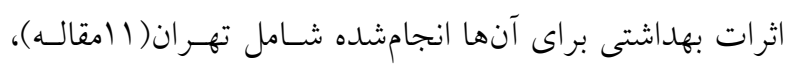

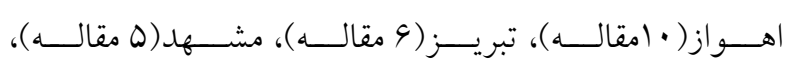

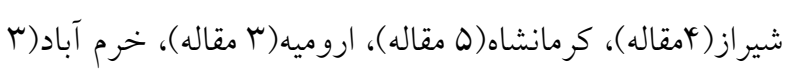

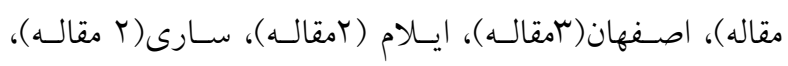

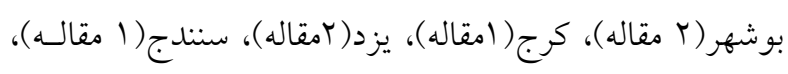

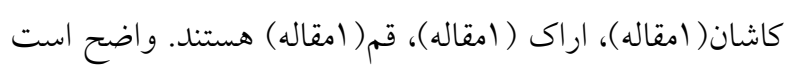

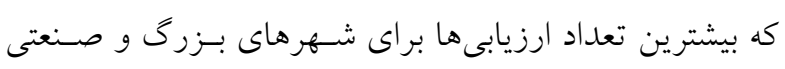

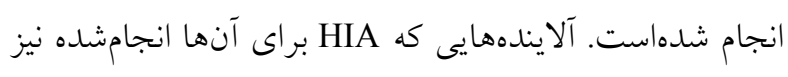

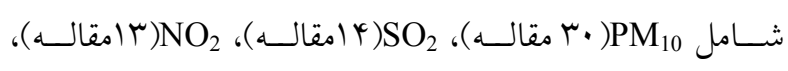
(ب)

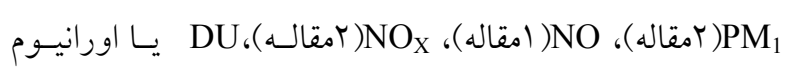

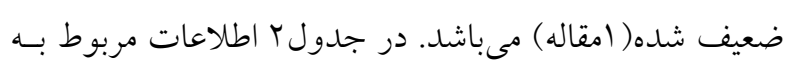

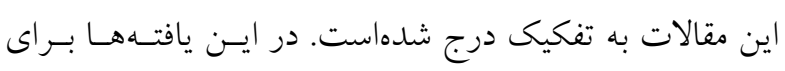

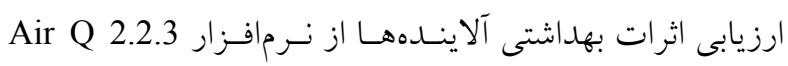


دموگر افيك(سن، جنس، وزن، سوابق شغلى و...) و بخش دوم

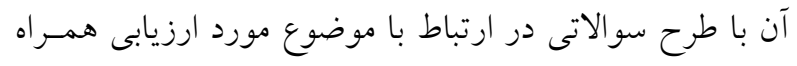

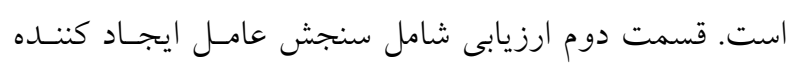

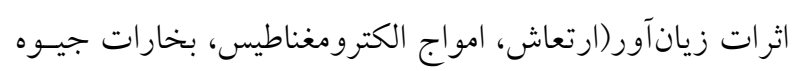

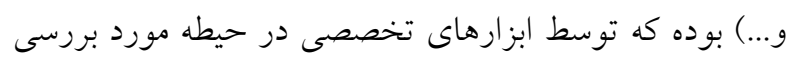

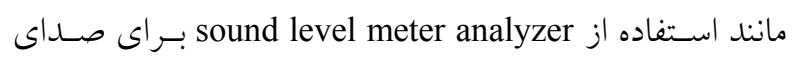

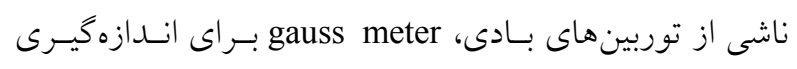

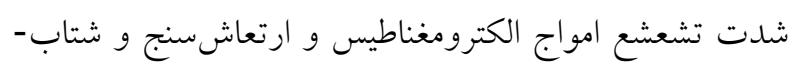

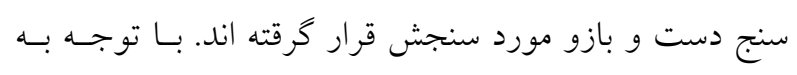

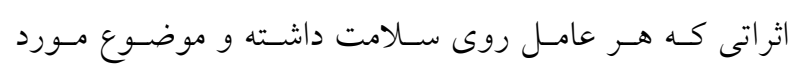

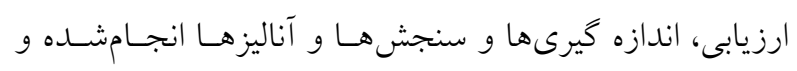

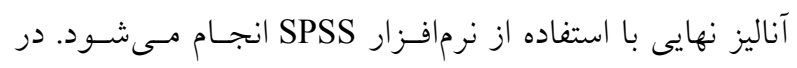
يايان نيز با توجه به ميزان اثرات و فاصله ایى كه با استانداردها

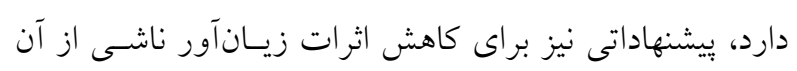

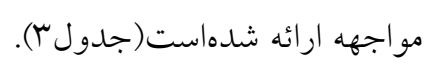

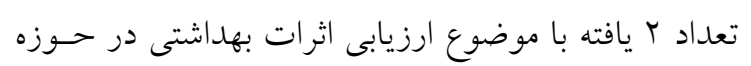

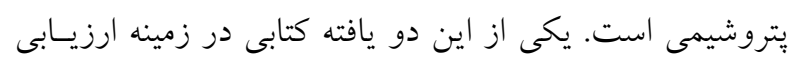

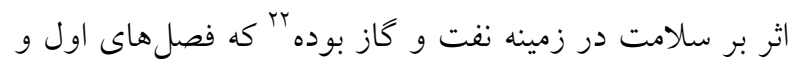

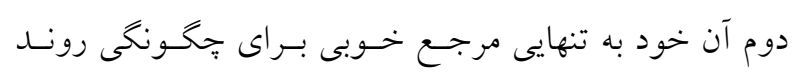

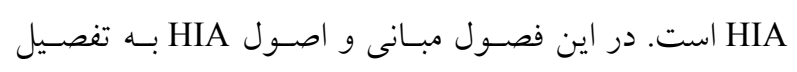

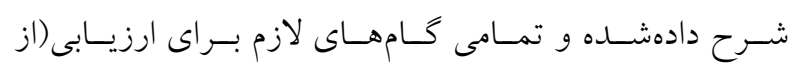

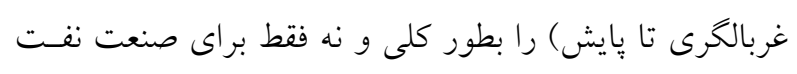

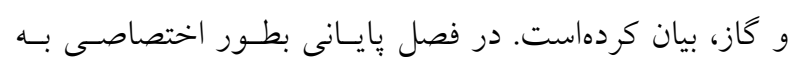

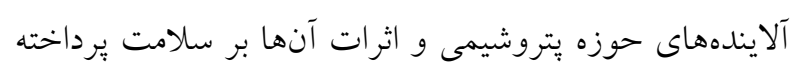

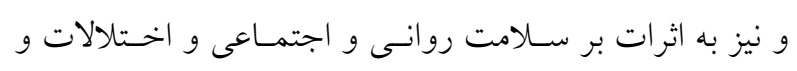

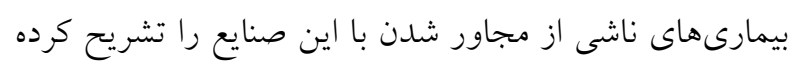

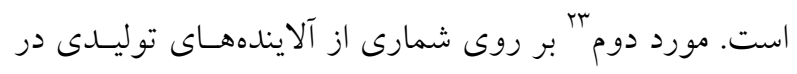

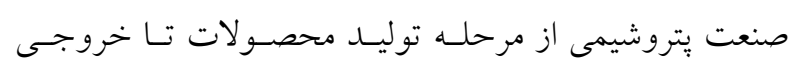

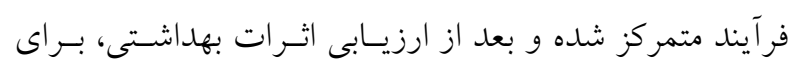

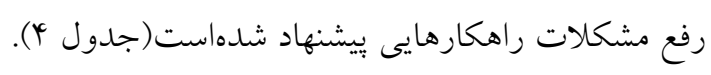

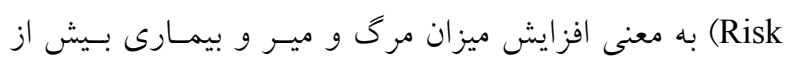

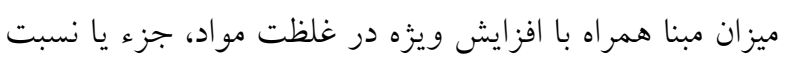

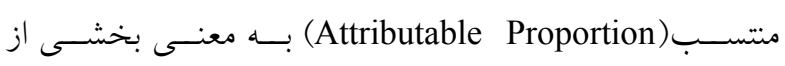

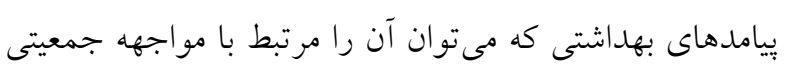

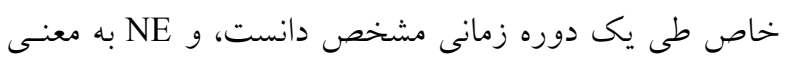

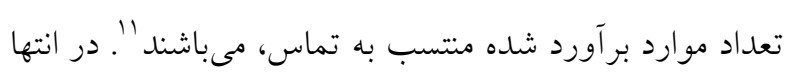

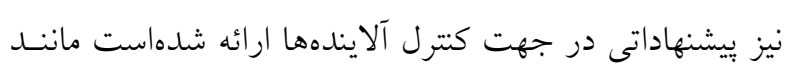
بهينهسازى سيستم حمل ونقل عمومى، رعايـت اسـتانداردهاى

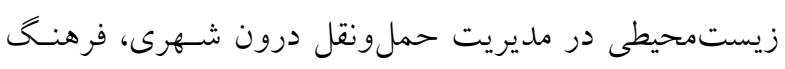

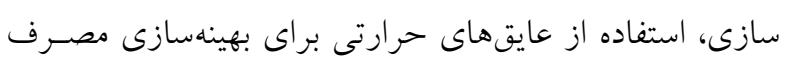

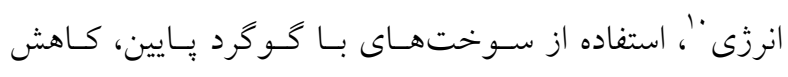

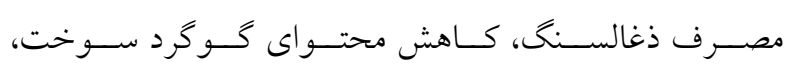

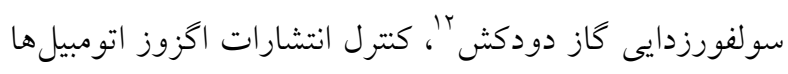
براى كاهش دىاكسيد نيتروزن در اتمسفر با، كتترل انتشـارات

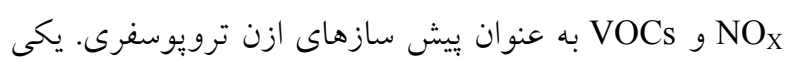

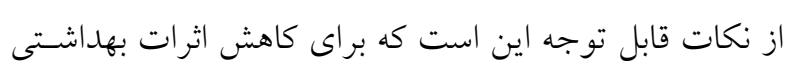

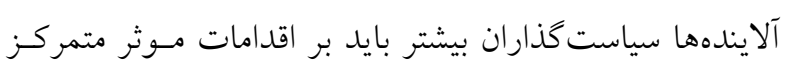

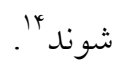
تعداد Vمقاله در زمينه ارزيابى اثـرات بهداشـتى در مـوارد

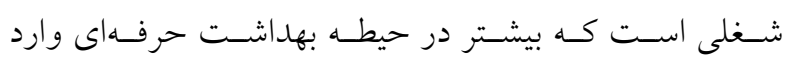

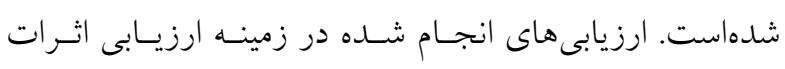

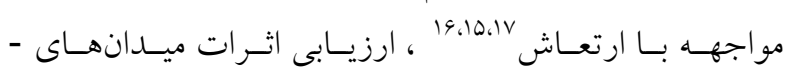

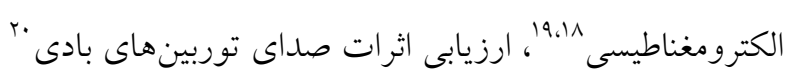

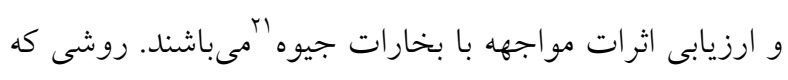

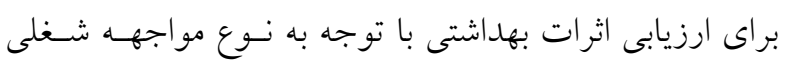

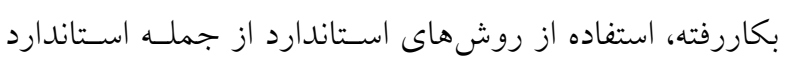

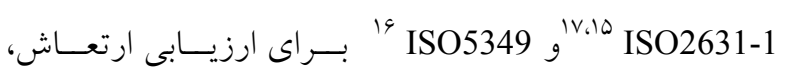

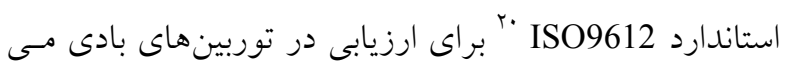

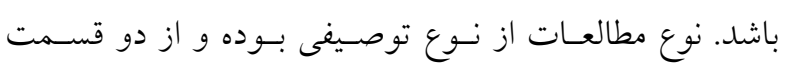

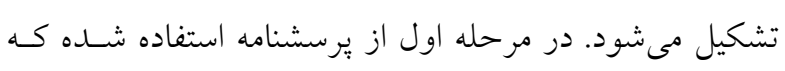
خــود شـامل دو بخـش اسـت : بخـش اول شـامل اطلاعـات 
در همخسى آنهـا بخشـى بـه سـو الات مربـوط بـه اطلاعـات

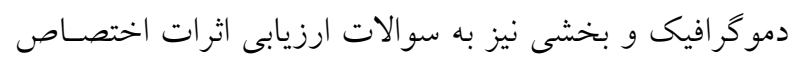

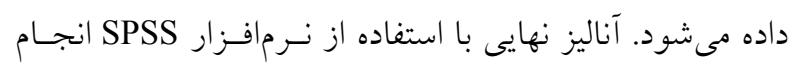

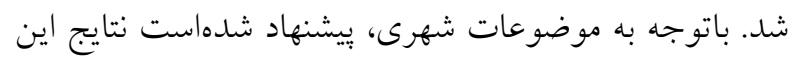

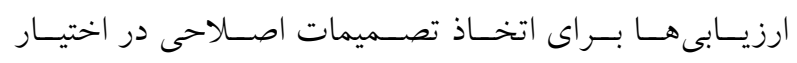

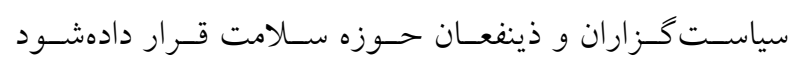

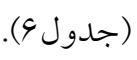

بافته در ارتباط با ارزيابى اثرات برخى عوامـل از جملـه.

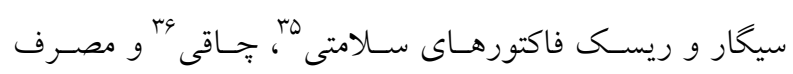

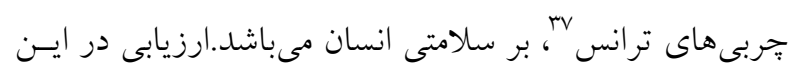

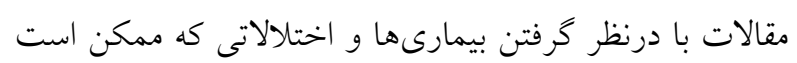

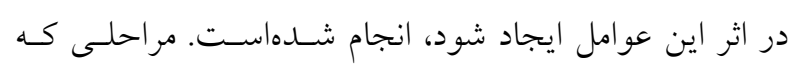

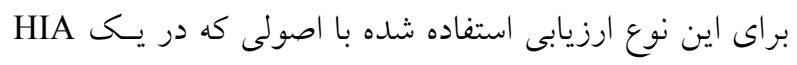

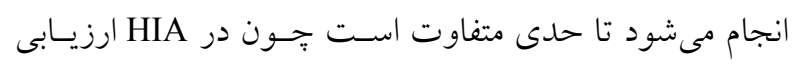

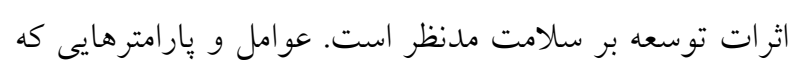

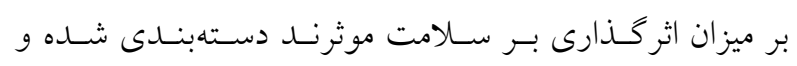

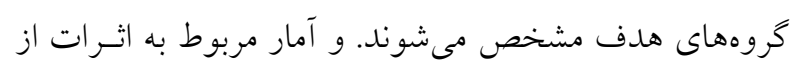

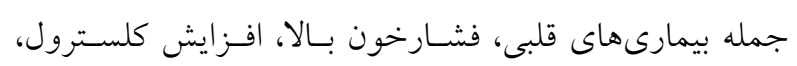

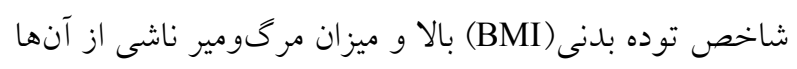

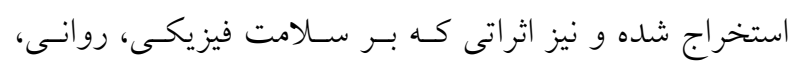

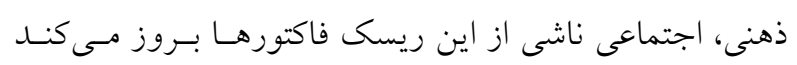

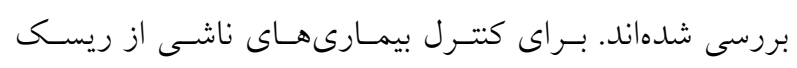

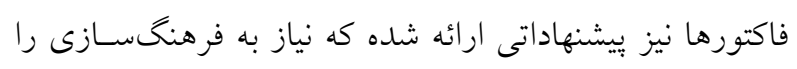

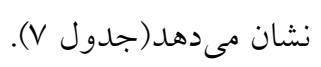

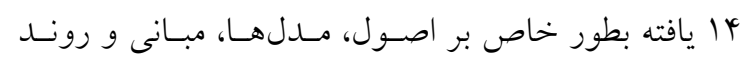

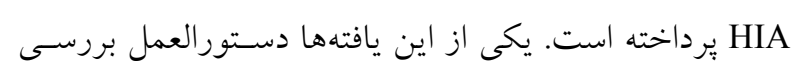

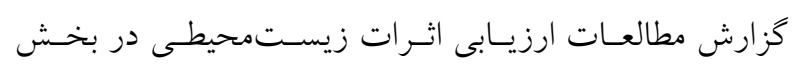

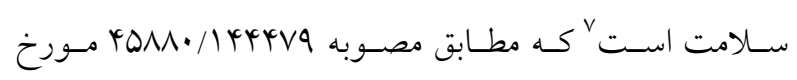

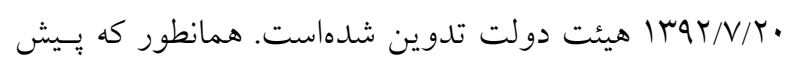

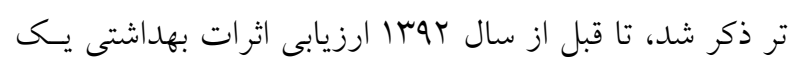

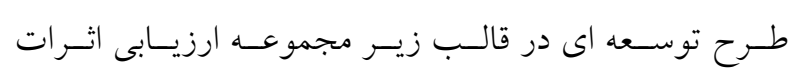

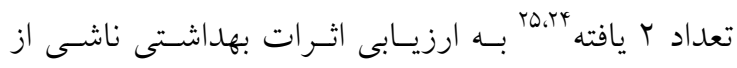

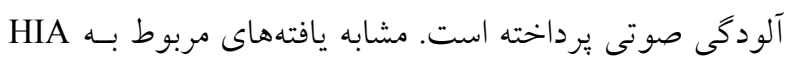

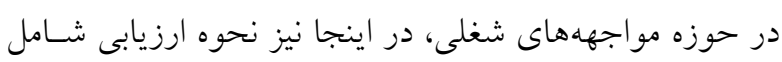

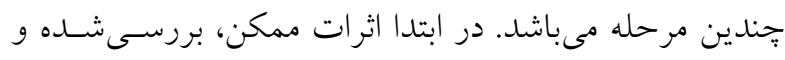
با استفاده از تجهيزاتى ماننــ sound level meter analyzer

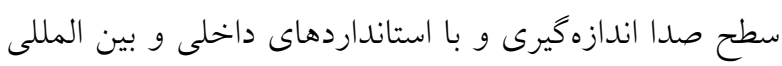

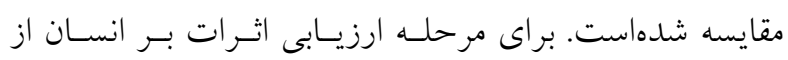

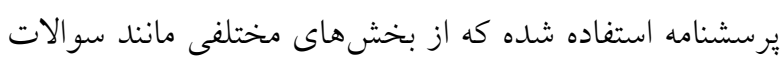

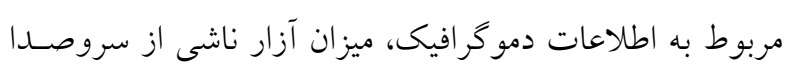

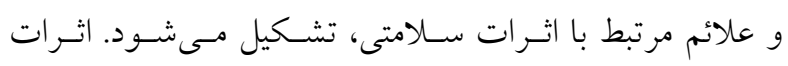

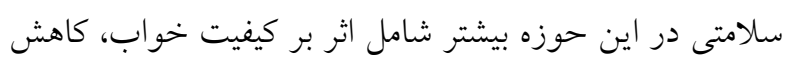

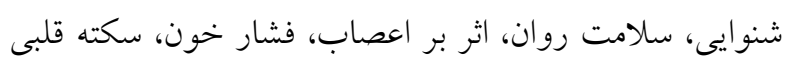

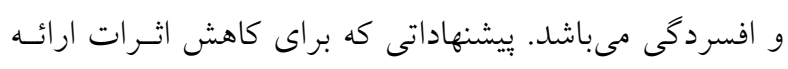

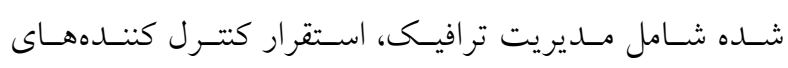

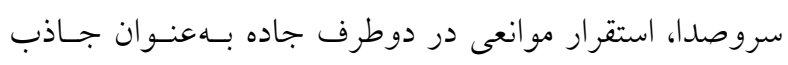
صدا، عايق كارى ساختمانهاى اطراف و... مى باشد. نـرمافـزار

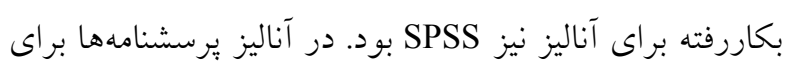

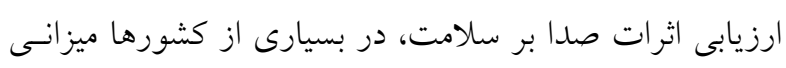

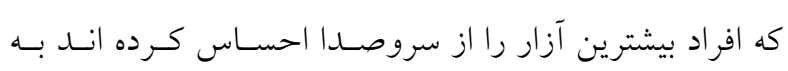

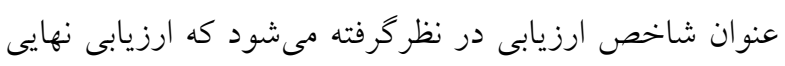

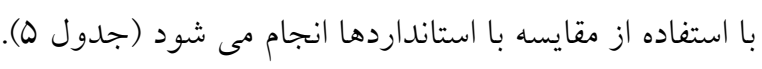

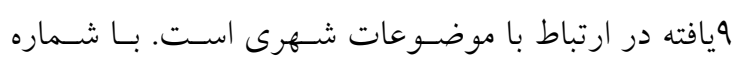

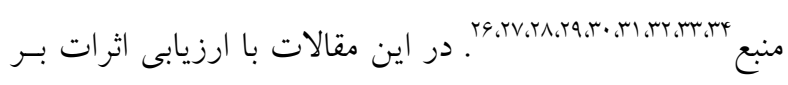

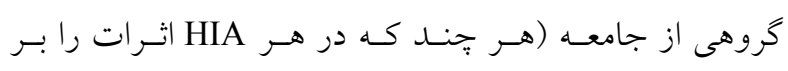

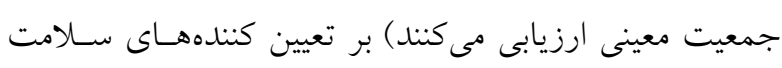

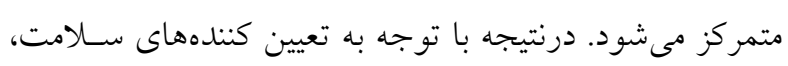

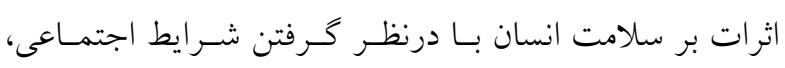

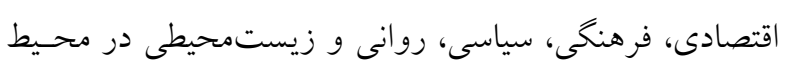

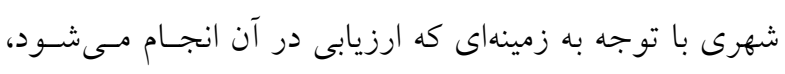

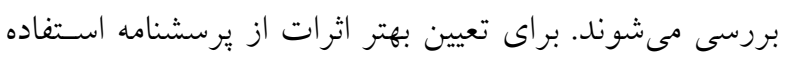

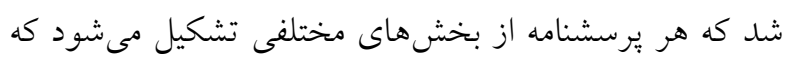




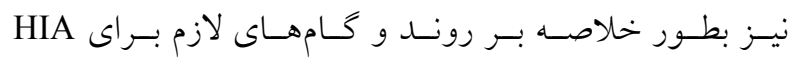
(غربــالكرى، تعيـين دامنــه، ارزيـابى، بيشــنهادات، يــايش و ارزشيابى) اشاره كردهاند(جدول ^). تعداد ·ل يافته نيز در گروهبندىهايى كه در بالا بيـان شـد قرار نخرفتهاست لذا بهصورت جداكانه بررسى مىشوند. ايسن مـوارد شـامل ارزيـابى اثـرات بهداشـتى در زمينـههـاى مـواد

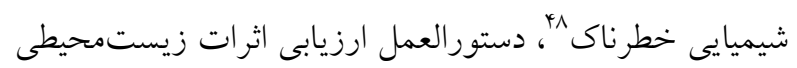
طرحهاى آب و فاضلاب ارزيابى اثرات بهداشتى بهعنوان زير مجموعهاى از EIA ارائسه

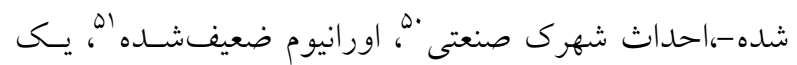

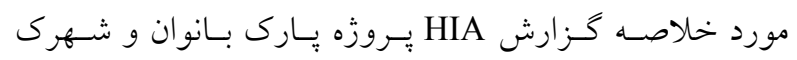
صـنعتى كاسـبين در قـزوين "، كيفيـت زنسـدكى در قربانيـان

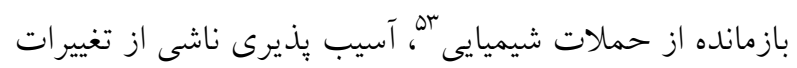

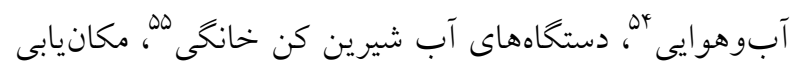

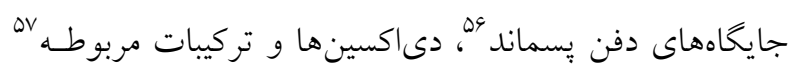
مىباشند. جزئيات مربوط به اين گروه در جدوله نشـان داده بهان
زيستمحيطى انجام مى شد كه اين دستورالعمل نحوه ارزيـابى اثرات بهاشتى در بروزههاى مشمول ارزيابى زيستـمحيطى

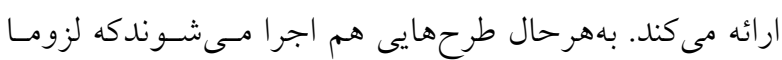
نيازى به EIA ندارد اما بـهـ HIA نيـاز دارد. بنـابراين در سـال

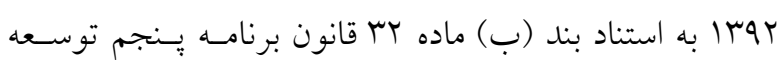

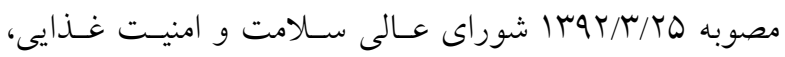

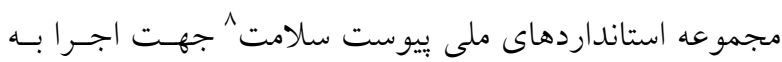
كليه دستخاههاى اجرايى ابلاغ شد. با تدوين ايـن اسـتانداردها براى طرحهاى توسعهاى بزرى صرفنظر از اينكه EIA انجام مىشود يا خير، HIA الزامسى اسـت. در ايسن استاندارد كليـه الزامات براى هر يك از گامهاى HIA و نحوه ارائه گزارشات تدوين شدهاست. در ارزيابى اثرات زيستمحيطى اغلب اثرات

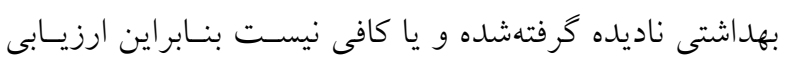
جداكانهاى در قالب HIA با اصول مربوط به خود، مسىتوانـا

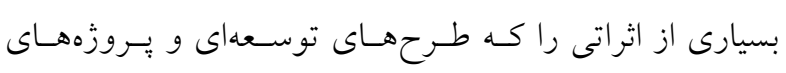

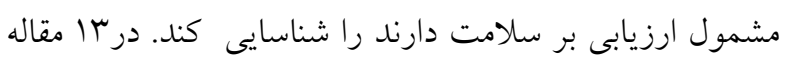

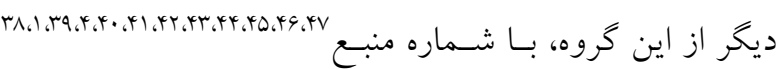

جدولr: يافتهاى ارزيابى اثرات بهداشتى در حوزه آلودگى هوا

\begin{tabular}{|c|c|c|c|c|c|c|}
\hline شماره منبع & يَايگاه داده & سال انتشار & سال مورد بررسى & محل & نوع آلاينده & نوع منبع \\
\hline$(\Delta \wedge)$ & $\begin{array}{l}\text { Web of } \\
\text { science }\end{array}$ & $T \cdot 19$ & $r \cdot 11$ & تبريز & $\mathrm{PM}_{10}$ & مقاله (متن كامل) \\
\hline$(\Delta 9)$ & Magiran & 1rat & $|r q|-q r$ & ايلام & $\mathrm{PM}_{10}$ & مقاله (متن كامل) \\
\hline (11) & Sid & س & $|r q|-9 r$ & ت تبريز & \multirow{2}{*}{$\begin{array}{l}\text { TPS- } \mathrm{PM}_{10} \\
\mathrm{PM}_{2.5}-\mathrm{PM}_{1} \\
\mathrm{PM}_{2.5} \mathrm{CO}\end{array}$} & مقاله (متن كامل) \\
\hline$(9 \cdot)$ & Google & 11790 & $1 r q$. & تهر ان - اروميه-اراك اهواز- & & مقاله (متن كامل) \\
\hline$(I T)$ & $\begin{array}{l}\text { Google } \\
\text { scholar }\end{array}$ & $T \cdot 19$ & $r \cdot 11-r \cdot 1 r$ & 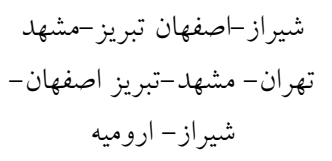 & $\mathrm{SO}_{2}$ & مقاله (من \\
\hline$(91)$ & Bio Med & $r \cdot 1 r$ & $r \cdots q$ & شيراز & $\mathrm{NO}_{2} \mathrm{PM}_{10^{-}} \mathrm{SO}_{2}$ & مقاله (متن كامل) \\
\hline$(G Y)$ & Civilica & Irar & $|r q \cdot-q|$ & 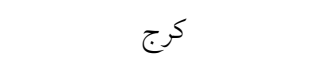 & $\mathrm{PM}_{10^{-}} \mathrm{O}_{3}$ & مقاله (جكيده) \\
\hline$(9 \pi)$ & $\begin{array}{l}\text { Google } \\
\text { scholar }\end{array}$ & $r \cdot 10$ & $r \cdot \mid r-r \cdot 1 r$ & 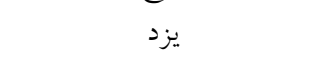 & \multirow{2}{*}{$\begin{array}{c}\mathrm{PM}_{10^{-}} \mathrm{PM}_{2.5} \\
\mathrm{SO}_{2} \\
\mathrm{PM}_{2.5}\end{array}$} & مقاله (متن كامل) \\
\hline$(94)$ & Google & 1790 & Irar & مشهد & & مقاله (متن كامل) \\
\hline$(90)$ & $\begin{array}{c}\text { Science } \\
\text { direct }\end{array}$ & $T \cdot 19$ & $r \cdot 1 r-r \cdot 10$ & مشهل & \multirow{2}{*}{$\begin{array}{l}\mathrm{PM}_{10^{-}}-\mathrm{PM}_{2.5} \\
\mathrm{SO}_{2}-\mathrm{NO}_{2}-\mathrm{O}_{3} \\
\mathrm{NO}_{2}\end{array}$} & مقاله (متن كامل) \\
\hline$(1 \mu)$ & Magiran & $r \cdot 19$ & $r \cdot 1 Y-r \cdot 10$ & كرمانشاه & & مقاله (متن كامل) \\
\hline$(99)$ & Embase & $r \cdot 19$ & $r \cdot 1 r-r \cdot 10$ & كرمانشاه & $\mathrm{O}_{3}$ & مقاله (متن كامل) \\
\hline$(9 \mathrm{~V})$ & Civilica & $1 \mathrm{MNO}$ & - & - & DU & مقاله (جكيده) \\
\hline
\end{tabular}


مرور سيستماتيك بر دوى بررسى جايكاه ارزيابى اثرات بر سلامت در ايران: تكامل، تحقيقات و زمينهاى بهبود آن

\begin{tabular}{|c|c|c|c|c|c|c|}
\hline$(9 \wedge)$ & Embase & $r \cdot 10$ & $r \cdot|r-r \cdot| r$ & شيراز - بوشهر & $\begin{array}{c}\mathrm{PM}_{10^{-}}-\mathrm{SO}_{2} \\
\mathrm{NO}_{2}-\mathrm{O}_{3}-\mathrm{CO}\end{array}$ & مقاله (جكيده) \\
\hline$(9)$ & Google & 1790 & $\mid r \wedge Y-\Lambda \Lambda$ & تهران & $\mathrm{CO}$ & مقاله (متن كامل) \\
\hline$(99)$ & $\begin{array}{l}\text { Google } \\
\text { scholar }\end{array}$ & $r \cdot 10$ & $r \cdot 14$ & ت تهران & $\mathrm{SO}_{2}-\mathrm{NO}_{2}-\mathrm{O}_{3}$ & مقاله (متن كامل) \\
\hline$(v \cdot)$ & $\begin{array}{l}\text { Google } \\
\text { scholar }\end{array}$ & 5.19 & $r \cdot \Delta-r \cdot \mid r$ & ت ت تهران & $\begin{array}{c}\mathrm{PM}_{10}-\mathrm{SO}_{2} \\
\mathrm{NO}_{2}-\mathrm{O}_{3}\end{array}$ & مقاله (متن كامل) \\
\hline (vi) & $\begin{array}{l}\text { Google } \\
\text { scholar }\end{array}$ & 1590 & Irar & ت ت تهران & $\begin{array}{c}\mathrm{PM}_{10^{-}} \mathrm{SO}_{2} \\
\mathrm{PM}_{2.5}\end{array}$ & مقاله (متن كامل) \\
\hline$(V Y)$ & $\begin{array}{l}\text { Science } \\
\text { direct }\end{array}$ & $r .19$ & $r \cdot \cdot q-r \cdot \mid r$ & المواز & $\mathrm{PM}_{10}$ & مقاله (متن كامل) \\
\hline$\left.(1)^{k}\right)$ & $\begin{array}{l}\text { Science } \\
\text { direct }\end{array}$ & 5.19 & $r \cdot 11-r \cdot 1 r$ & كرمانشاه & $\mathrm{PM}_{10}$ & مقاله (متن كامل) \\
\hline$(V \mu)$ & $\begin{array}{l}\text { Google } \\
\text { scholar }\end{array}$ & $r \cdot 10$ & $r .11$ & اهو از & $\mathrm{NO}_{2}$ & مقاله (متن كامل) \\
\hline$\left(V{ }^{*}\right)$ & Bio Med & $r \cdot I r$ & $r \cdot 1 \cdot-r \cdot 11$ & ت تهر ان & $\begin{array}{c}\mathrm{PM}_{10^{-}} \mathrm{SO}_{2} \\
\mathrm{NO}_{2}-\mathrm{O}_{3}\end{array}$ & مقاله (متن كامل) \\
\hline$(V Q)$ & $\begin{array}{l}\text { Science } \\
\text { direct }\end{array}$ & $r \cdots Q$ & $1999-Y \cdots 1$ & ت تهران & $\begin{array}{l}\mathrm{PM}_{10^{-}}-\mathrm{SO}_{2} \\
\mathrm{NO}_{2}-\mathrm{O}_{3}-\mathrm{CO}\end{array}$ & مقاله (متن كامل) \\
\hline$(1 \cdot)$ & Magiran & 1790 & Irar & اروميه & $\mathrm{PM}_{10^{-}} \mathrm{SO}_{2}$ & مقاله (متن كامل) \\
\hline (Vq) & $\begin{array}{l}\text { Google } \\
\text { scholar }\end{array}$ & $r \cdot 10$ & $r \cdot 14$ & خرم آباد & $\mathrm{PM}_{10}$ & مقاله (متن كامل) \\
\hline$(\mathrm{V})$ & $\begin{array}{l}\text { Google } \\
\text { scholar }\end{array}$ & $r \cdot 10$ & $r \cdot 14$ & خرم آباد- ايلام & $\mathrm{PM}_{10}$ & مقاله (متن كامل) \\
\hline$(\mathrm{V} \wedge)$ & $\begin{array}{l}\text { Google } \\
\text { scholar }\end{array}$ & $r .19$ & $r \cdot 14$ & خرم آباد & $\mathrm{PM}_{10}$ & مقاله (متن كامل) \\
\hline (Vq) & Bio Med & $r \cdot I^{t}$ & $r \cdot \mid r-r \cdot 1 r$ & 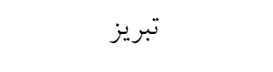 & $\begin{array}{l}\text { TPS- } \mathrm{PM}_{10} \\
\text { PM }_{2.5}-\mathrm{PM}_{1}\end{array}$ & مقاله (متن كامل) \\
\hline$(\Lambda \cdot)$ & $\begin{array}{l}\text { Google } \\
\text { scholar }\end{array}$ & $r \cdot I^{k}$ & $r \cdot 1 r$ & سنندج & $\mathrm{PM}_{10}$ & مقاله (متن كامل) \\
\hline$(\wedge 1)$ & Magiran & Irar & IrMA & الهواز & $\mathrm{NO}_{2}$ & مقاله (متن كامل) \\
\hline$(\Lambda Y)$ & Magiran & trat & IrMA & اهواز & $\mathrm{PM}_{10}$ & مقاله (متن كامل) \\
\hline (Ar) & $\begin{array}{l}\text { Google } \\
\text { scholar }\end{array}$ & $r \cdot 1 r$ & $r \cdot I r$ & الهواز & $\mathrm{PM}_{10}$ & مقاله (متن كامل) \\
\hline$\left.(\lambda)^{k}\right)$ & Magiran & rar & $14 q$. & تبريز & $\mathrm{PM}_{10}$ & مقاله (متن كامل) \\
\hline$(\Lambda \Delta)$ & $\begin{array}{l}\text { Google } \\
\text { scholar }\end{array}$ & $r \cdot I V$ & $r \cdot q q$ & ال اهو از & $\mathrm{PM}_{10}$ & مقاله (متن كامل) \\
\hline$(\wedge \varsigma)$ & $\begin{array}{l}\text { Google } \\
\text { scholar }\end{array}$ & $r .19$ & $r \cdot i r$ & المواز & $\mathrm{O}_{3}$ & مقاله (متن كامل) \\
\hline$(\wedge \vee)$ & Magiran & $r \cdot 10$ & $r .11$ & كاشان & $\begin{array}{c}\mathrm{PM}_{10}-\mathrm{SO}_{2} \\
\mathrm{NO}_{2}-\mathrm{O}_{3}\end{array}$ & مقاله (متن كامل) \\
\hline$(\Lambda \Lambda)$ & Civilica & ITNV & - & 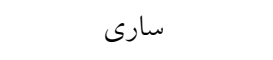 & $\mathrm{SO}_{2}-\mathrm{O}_{3}$ & مقاله (جكيده) \\
\hline$(\wedge 9)$ & Civilica & $|r q|$ & - & سارى & PM & مقاله (جكيده) \\
\hline$(9 \cdot)$ & Embase & $r \cdot 19$ & $r \cdot 1 r$ & مشهد & $\mathrm{PM}_{2.5}$ & مقاله (متن كامل) \\
\hline (91) & $\begin{array}{l}\text { Web of } \\
\text { science }\end{array}$ & $r .19$ & $r \cdot 1$. & تهران & $\mathrm{NO}_{\mathrm{X}}-\mathrm{NO}-\mathrm{NO}_{2}$ & مقاله (متن كامل) \\
\hline$(9 r)$ & $\begin{array}{l}\text { Google } \\
\text { scholar }\end{array}$ & $r \cdot I^{t}$ & $r .11$ & اهواز - كرمانشاه- بوشهر & $\mathrm{NO}_{2}$ & مقاله (متن كامل) \\
\hline$(9 r)$ & Google & $1 r q$. & $1 \pi q$. & 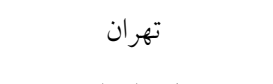 & $\begin{array}{l}\mathrm{PM}_{10^{-}} \mathrm{SO}_{2} \\
\mathrm{NO}_{2}-\mathrm{O}_{3}-\mathrm{CO}\end{array}$ & "يايانامه (جكيده) \\
\hline$(94)$ & Scopus & $r \cdot I V$ & $r \cdot 1 Y-r \cdot 10$ & كرمانشاه & $\mathrm{PM}_{10}$ & مقاله (جكيده) \\
\hline$(90)$ & Scopus & $r \cdot I V$ & $r \cdot \Delta-r \cdot \mid r$ & تهران & $\mathrm{PM}_{10}$ & مقاله (جكيده) \\
\hline$(99)$ & Scopus & $r \cdot I V$ & $r \cdot .9-r \cdot 1 r$ & ال اهو از & $\mathrm{PM}_{10}$ & مقاله (جكيده) \\
\hline$(9 \mathrm{~V})$ & Scopus & $r \cdot I V$ & - & اصفهان & $\mathrm{PM}_{2.5}$ & مقاله (جكيده) \\
\hline$(9 \wedge)$ & PubMed & $r .19$ & $r \cdot 11$ & قم & $\begin{array}{c}\mathrm{PM}_{10}-\mathrm{SO}_{2} \\
\mathrm{NO}_{\mathrm{x}}-\mathrm{CO}\end{array}$ & مقاله (متن كامل) \\
\hline$(99)$ & PubMed & $r \cdot I V$ & $r \cdot 1 r$ & يزد & $\mathrm{PM}_{10}$ & مقاله (متن كامل) \\
\hline
\end{tabular}


ادريس حسين زاده و همكاران

جدولس": يافتهاى ارزيابى اثرات بهداشتى در حوزه موارد شغلى و بهداشت حرفهاى

\begin{tabular}{|c|c|c|c|c|}
\hline شماره منبع & يايخاه داده & سال انتشار & 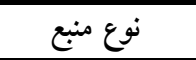 & حيطه ارزيابى \\
\hline$(10)$ & Magiran & irar & مقاله (متن كامل) & مو اجهه با ارتعاش در تمام بدن \\
\hline (19) & Google & 11490 & 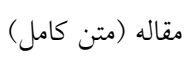 & مو اجهه با ارتعاش دست و بازو در كارگران سنگبرى \\
\hline$(I V)$ & Google & 11990 & 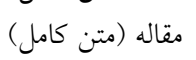 & مو اجهه با ارتعاش بدن در مسافرين مترو \\
\hline$(1 \wedge)$ & Sid & IHAV & 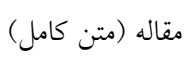 & مواجهه با ميدانهاى الكترومغناطيسى نمايشخرها \\
\hline$\left(r_{\cdot}\right)$ & Bio Med & $r \cdot 10$ & 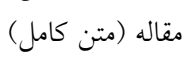 & مواجهه با صداى توربينهاى بادى \\
\hline$(Y)$ & Magiran & $1 r \wedge 9$ & 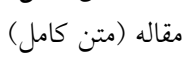 & مو اجهه با بخارات جيوه در واحد كلر آلكالى \\
\hline \multirow[t]{2}{*}{ (19) } & Google & Irat & مقاله (جكيده) & مو اجهه با ميدانهاى الكترومغناطيسى توسط كاركنان مجاور خطوط \\
\hline & & & & انتقال نيرو \\
\hline
\end{tabular}

\begin{tabular}{|c|c|c|c|c|}
\hline شماره منبع & يَايخاه داده & سال انتشار & نوع منبع & حيطه ارزيابى \\
\hline$(Y \mu)$ & Civilica & irar & مقاله (جكيده) & ارزيابى اثرات سوء زيستمحيطى با تاكيد بر ارزيابى ريسك \\
\hline$(Y Y)$ & Google & $|r q|$ & كتاب & راهنماى ارزيابى اثر بر سلامت در صنعت نفت و گاز \\
\hline
\end{tabular}

\begin{tabular}{|c|c|c|c|c|}
\hline شماره منبع & يايگاه داده & سال انتشار & نوع منبع & حيطه ارزيابى \\
\hline$(Y Y)$ & Science direct & $r \cdot 14$ & مقاله (متن كامل) & اثر آلودكى صوتى در فرودكاه با توجه به كاربرى زمين \\
\hline$(Y Q)$ & Magiran & $r \cdot 10$ & 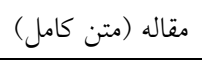 & اثر آلودگى صوتى در مجاورت جادهها \\
\hline
\end{tabular}

\begin{tabular}{|c|c|c|c|c|c|}
\hline شماره منبع & يايگگاه داده & سال انتشار & مكان & 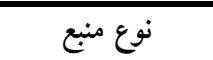 & 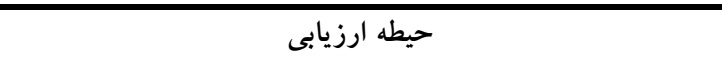 \\
\hline$(Y q)$ & Science direct & $r \cdot 1 T$ & هشتخرد & 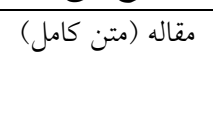 & 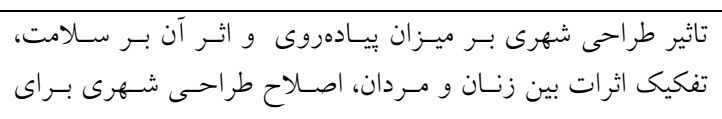 \\
\hline$(Y V)$ & Science direct & $r \cdot 10$ & 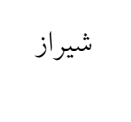 & 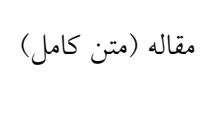 & 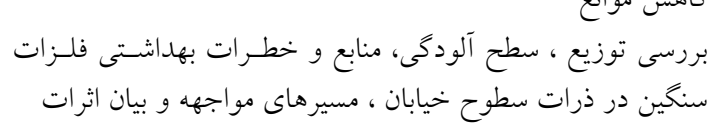 \\
\hline$(Y \wedge)$ & Bio Med & $r \cdot \cdot q$ & آذ آذربايجان & 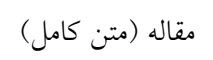 & بررسى جالشها و الزامات در كاهش صدمات جاده اى، \\
\hline$(r q)$ & Science direct & $r .19$ & قم & 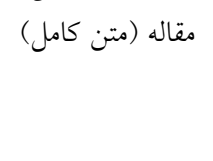 & 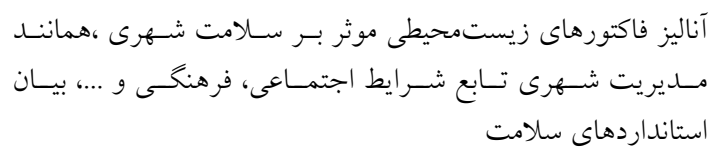 \\
\hline$(r \cdot)$ & Magiran & $r \cdot 14$ & سنندج & مقاله (متن كامل) & اثرات ترافيك بر تعيين كنندهاى سلامت، استفاده از رهنمودهـاى \\
\hline$(M)$ & Civilica & $|r q|$ & - & مقاله (جكيده) & كاربرد ارزيابى اثرات بهداشتى در بروزههاى عمران شهرى \\
\hline$(M r)$ & Google & Irar & تهران & يايان نامه (جكيده) & 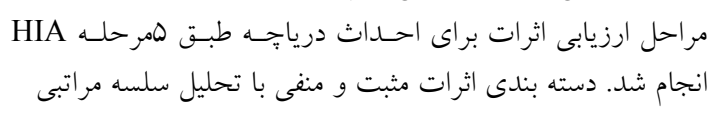 \\
\hline (Tr) & Google & $|r q|$ & - & 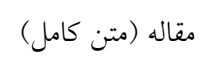 & نحوه تاثير برنامههاى حمل و تقل بر سلامت، تاثير بر فعاليتهـاى \\
\hline$(M Y)$ & PubMed & $r \cdot 14$ & تهران & 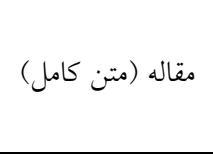 & بلدنى و امكان يِيادهروى بندى اثرات يروزهاى توسعه شهرى بــر تعيـين كنــده هـاى \\
\hline
\end{tabular}


مرور سيستماتيك بر روى بررسى جايكاه ارزيابى اثرات بر سلامت در ايران: تكامل، تحقيقات و زمينهاى بهبود آن

جدولV: يافتهاى ارزيابى اثرات بهداشتى در حوزه سلامت

\begin{tabular}{|c|c|c|c|c|}
\hline شماره منبع & يايگًاه داده & سال انتشار & نوع منبع & حيطه ارزيابى \\
\hline$(r \Delta)$ & Bio Med & $r \cdot 11$ & مقاله (متن كامل) & 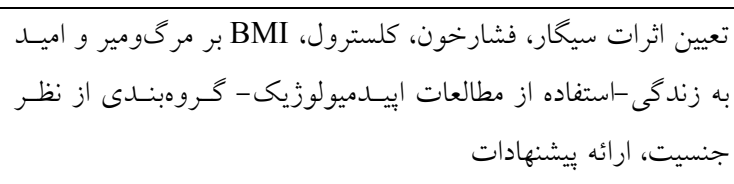 \\
\hline$(\pi 4)$ & Embase & $r \cdot 10$ & مقاله (متن كامل) & روارائه رهنمود براى اضافه وزن - اثرات جسمى، ذهنى، اجتمـاعى و \\
\hline$(M V)$ & Google scholar & $r \cdots v$ & مقاله (متن كامل) & 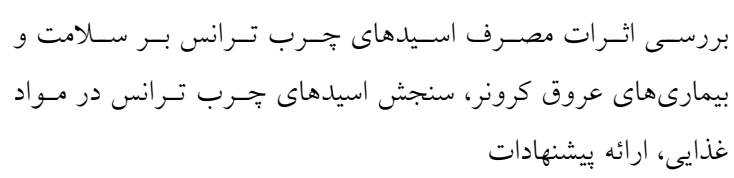 \\
\hline
\end{tabular}

جدولم: يافتههاى ارزيابى اثرات بهداشتى در حوزه اصول HIA

\begin{tabular}{|c|c|c|c|c|}
\hline شماره منبع & 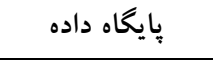 & سال انتشار & 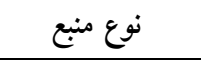 & حيطه ارزيابى \\
\hline$(\mathrm{V})$ & Google & - & دستور العمل & درستور العمل بررسى گزارش مطالعات ارزيابى اثرات زيست محيطى \\
\hline$(\wedge)$ & Google & irat & 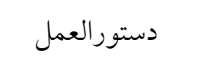 & استاندارد ملى بيوست سلامت \\
\hline$(k+)$ & Google & $|r q|$ & مقاله (ֶ)كيده) & توزعهابى اثرات سلامت، رويكردى نوين در ارزيابى اثرات طرحهاى \\
\hline$(\uparrow \wedge)$ & Magiran & irat & 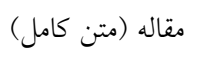 & الكويى براى ارزيابى اثرات بهداشتى طرحهاى توسعهاى در ايران \\
\hline (1) & Magiran & irat & 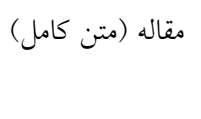 & آن ارزيابى اثرات بهداشتى طرحهاى توسعهاى و عوامل زمينهاى موثر بر \\
\hline$(\boldsymbol{M r})$ & Civilica & $|r q|$ & 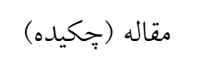 & ارزيابى اثرات بهلداشتى، مفاهيم، مراحل اجرا و كاربردها \\
\hline$(k+4)$ & Google scholar & $\operatorname{lrM}$ & 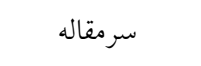 & ارزيابى اثرات توسعه بر سلامت محيط \\
\hline$(\varphi \Delta)$ & Civilica & IrM & 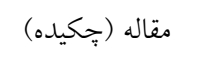 & مرورى بر ارزيابى اثرات بهداشتى، خارجوب ساختارى و انواع آن \\
\hline$(r q)$ & Magiran & $r \cdot 14$ & 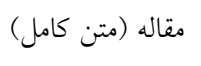 & بررسى اصول اساسى براى هدايت ارزيابى اثرات سلامت \\
\hline$(\boldsymbol{c})$ & Bio Med & $r \cdot 10$ & 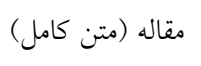 & ارائه جِارجهوبى براى ارزيابى اثرات بهداشتى در ايران \\
\hline$(\boldsymbol{c} \cdot)$ & Bio Med & $r .19$ & 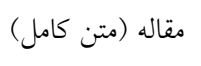 & ارزيابى اثر تحقيقات بهداشتى در ايران \\
\hline$(4)$ & Bio Med & $r \cdot 14$ & 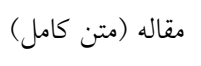 & نابر ابرى سلامتى و طرحهاى توسعه ایى در ايران \\
\hline$(49)$ & Sid & $\mid r q 1$ & مقاله (متن كامل) & مرور مدلهاى ارزيابى اثرات بر سلامت \\
\hline$(\& \vee)$ & PubMed & $r \cdot 19$ & مقاله (متن كامل) & بين المللى رهنمود هاى HIA در تحقيقات داخلى و مقايسه با منابع \\
\hline
\end{tabular}


ادريس حسين زاده و همكاران

جدول99: يافته هاى ارزيابى اثرات بهداشتى در ساير موضوعات

\begin{tabular}{|c|c|c|c|c|c|c|}
\hline شماره منبع & يايگاه داده & سال انتشار & مكان & نوع منبع & حيطه ارزيابى & ملاحظات \\
\hline$(\Psi \wedge)$ & Civilica & IrMA & - & (ج) & مواد شيميايى & 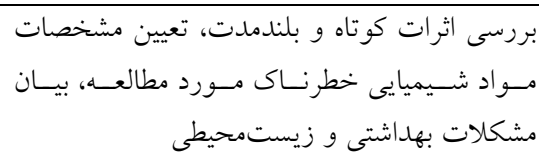 \\
\hline$(149)$ & Google & IrND & - & دستور العمل & طرحهاى آب و & 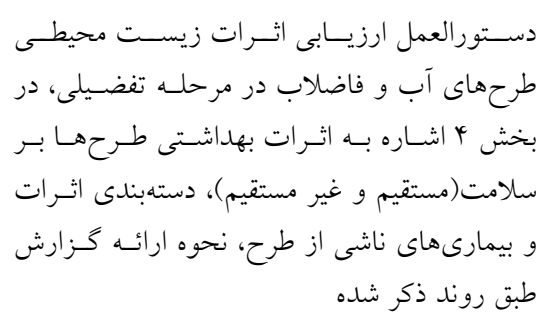 \\
\hline$(\Delta \cdot)$ & Sid & IrM & سبزوار، & (مقاله & هاى صاث شهرى & 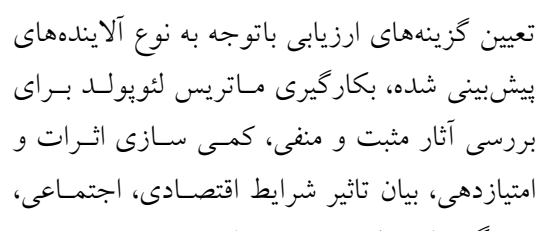 \\
\hline$(01)$ & Civilica & ITAV & - & (جقاله & شاورانيوم ضعيف & 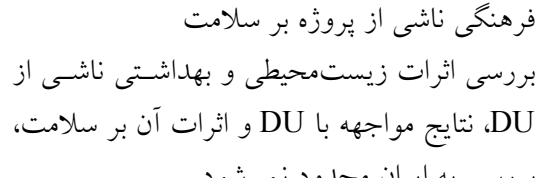 \\
\hline$(D Y)$ & Google & $1 \pi q$. & قزوين & خزارش خلاصه & 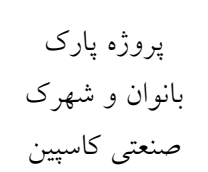 & 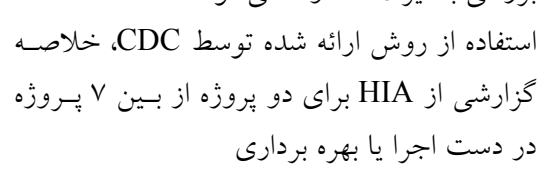 \\
\hline$(\Delta r)$ & Bio Med & $r \ldots q$ & - & (متن كامل) & كيفيت زندگ حمازماند & 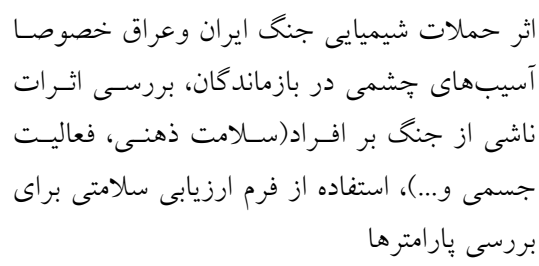 \\
\hline$(\Delta K)$ & Civilica & rate & - & (جقاله & نآشى آزيب يذيرى تغييرات & 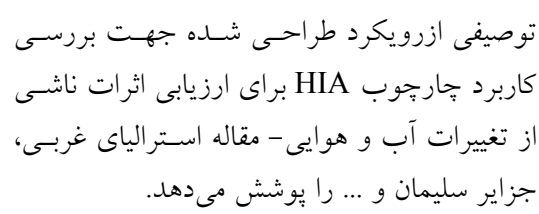 \\
\hline$(\Delta \Delta)$ & Google & 1 IMN & قم & نتيجه يروزه & شستخاه آب شين كن & 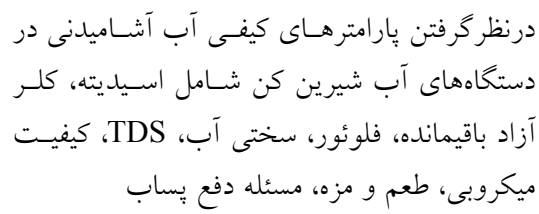 \\
\hline$(\Delta \varphi)$ & Google & 1790 & - & (ج) مقاله & مكان يابى جايعاه & و بيان نقش آن ارزيابى اثرات بهداشتى و زيستمحيطى محان \\
\hline$(\Delta V)$ & $\begin{array}{l}\text { Barakat } \\
\text { knowledge } \\
\text { network }\end{array}$ & IrNo & - & (ج) & تركيبات مربوطه و و و & 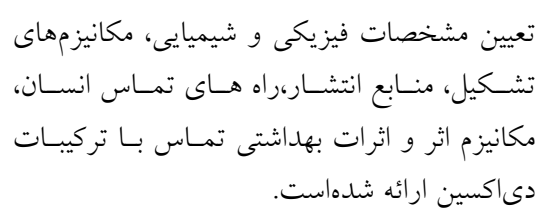 \\
\hline
\end{tabular}




$$
\begin{aligned}
& \text { را ارزيابى اثرات آلايندههاى هوا بر سلامت به خود اختصاص } \\
& \text { مى دهل. با دقت به مكان آن نيز واضح است كه اين ارزيـابى } \\
& \text { در شهرهاى بزركى انجام شده كه آلـودگى هـوا از معضـلات }
\end{aligned}
$$

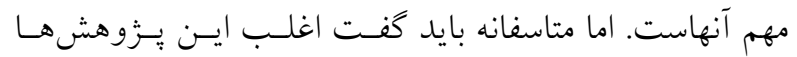

$$
\begin{aligned}
& \text { صرفا نتايج و بيشنهاداتى روى كاغذ اسـت كـه سـودى عايسـد } \\
& \text { مردم نمى كند. انجام اقدامات لازم براى اعمال يِيشنهادات ارائه } \\
& \text { شده در حيطـه اختيـارات مسـئولين حـوزه سـالمت و سـاير } \\
& \text { مسئولين ذينفع در حوزههاى مختلف مى باشد. موضوعاتى كـه } \\
& \text { در اين مرور سيستماتيك نيز گردآورى شده تنها به يك طـرح } \\
& \text { يا يروزه محدود نمىشود و براى بيادهسازى اقدامات مناسـب، } \\
& \text { به برنامهريزى هاى بلندمدت نياز دارد كـه بـا ورود } \\
& \text { طرحهاى ملى اين انتظار و اميد وجــود دارد كـه مسـئولين بـر }
\end{aligned}
$$

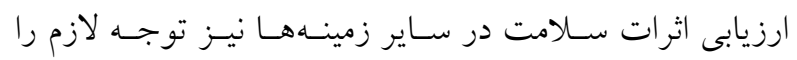

$$
\begin{aligned}
& \text { مبذول دارند و يزّوهشهاى انجام شـــه مسى توانــ بـهـ عنـوان } \\
& \text { راهنما و خط مبنايى براى ارزيـابىهـاى جـامعتـر و بـهـ ثمــر } \\
& \text { رسيدن نتايج آن باشد. }
\end{aligned}
$$

\section{References}

1. Fakhri A, Maleki MR. Health Impact Assessment and its Contextual Influencing Factors in Iran. Hakim Health Syst Res J 2016;18(4):316-28 [In Persian].

2. Environmental Impact Assessment of Development Projects. Iran Environmental Protection Agency; 2008. Available from: http://isfahandoe.ir/dorsapax/userfiles/file/eia/pdf [In Persian].

3. Harris-Roxas B, Viliani F, Bond A, et al. Health Impact Assessment: The State of the Art. Impact Assessment \& Project Appraisal J 2012;30(1):43-52.

4. Fakhri A, Harris P, Maleki M. Proposing a Framework for Health Impact Assessment in Iran. BMC public health $\mathrm{J}$ 2015;15(1):335.

5. Grant S, Wilkinson J, Learmonth L. An Overview of Health Impact Assessment. 2001 Available from: http://dro.dur.as.uk/5613/1/5613.pdf.

6. Mindell J, Sheridan L, Joffe M, et al. Health Impact Assessment as an Agent of Policy Change: Improving the Health Impacts of the mayor of London's draft transport strategy. J epidemiol \& Community Health 2004;58(3):169-74.

\section{نتيجه گيرى}

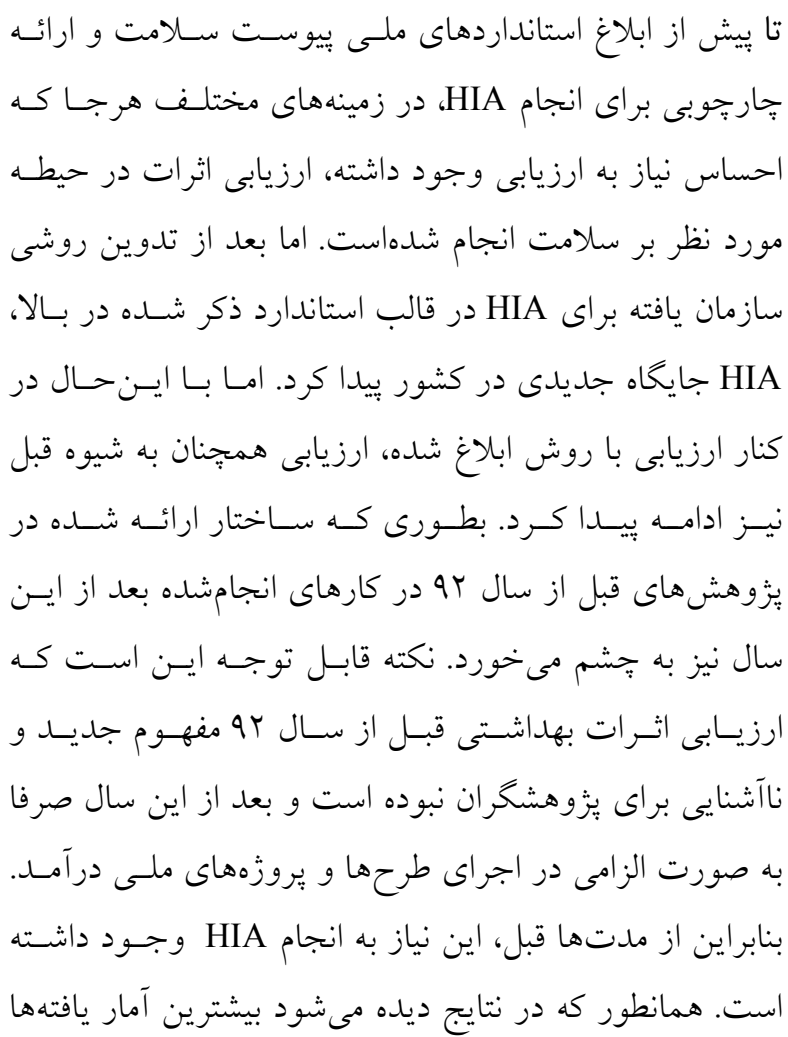

7. Instruction Survey Report on Environmental Impact Assessment in Health Sector. Available from: http://daneshtestanhc.bpums.ac.ir [In Persian].

8. National Health Standards Requiement of Iran 2013. Available from: http://vcm.iums.ac.ir/uploads/estandard_pavast_salamat.p df [In Persian]

9. Kermani M, Dowlati M, Jonidi Jafari A, Rezaei R. Study the Number of Cases Cardiovascular Mortality Attributed to $\mathrm{CO}$ in Tehran in during a five-year. Rahavard Salamat J 2016;2(3):38-47 [In Persian].

10. Khorsandi H, Karimzadeh S, Aghaei M, et al. Health Impact Assessment of Exposure to $\mathrm{Pm} 10$ and $\mathrm{SO} 2$ in Urmia City by AirQ Model. Urmia Med J 2016;27(5):438-48 [In Persian].

11. Gholampoor A, Nabizadeh R, Hassanvand $\mathrm{M}$, et al. Evalution of Particulate Matter Concentration in Ambient Air and Related Health Impact in Tabriz City. Iran J Health \& Environ 2014;7(4):541-56 [In Persian].

12. Kermani M, Jokandan SF, Aghaei M,et al. Estimation of the Number of Excess Hospitalizations Attributed to Sulfur Dioxide in Six Major Cities of Iran. Health Scope. 2016;5(4). DOI: 10.17795/jhealthscope-38736. 


$$
\text { ادريس حسين زاده و همكاران }
$$

13. Omidi Y, Goudarzi G ,Heidari AM, Daryanoosh SM. Health Impact Assessment of Short-term Exposure to NO2 in Kermanshah, Iran Using AirQ Model. Environ Health Eng Manage J 2016. DOI 10.15171/ehemj.2016.06.

14. Marzouni MB, Alizadeh $\mathrm{T}$, Banafsheh MR,et al. A Comparison of Health Impacts Assessment for PM10 During two Successive years in the Ambient Air of Kermanshah, Iran. Atmos Pollut Res J 2016;7(5):768-74.

15. Azrah K, Safari Z. Health Impact Assessment Guide of Exposure to Whole Body Vibration. HSE J 2012;3(1):2-7 [In Persian].

16. Bayat R, Aliabadi M, Golmohammadi R, Shafiee motlagh M. Assessment of Vibration Exposure in Hand and Arm and Related Health Effcts in Stone cuttings Workers in Hamedan City. J Occup Hygiene Eng 2017;3(1). DOI: 10.21859/johe-03014 [In Persian].

17. Azrah K, Mirzaei R, Biglari H,et al. Evaluation of Health Effects of Exposure to Whole Body Vibration in Seated and Standing Metro Passengers. J Acoustical Soc Iran 2015;2(2):59-69 [In Persian].

18. Mahmoudi A, Nasiri P, Zerati H, Farzanenezhad A. Health Impact Assessement of Magnetic and Electric Fields of Monitor Terminals in Users in Tehran University of Medical Sciences. J Environ Sci Tech 2008;10(1):91-102 [In Persian].

19. Torkian A, Monazzam M, Dastforoushan G. assessment of exposure rate in personnel next to the power transmission lines with electromagnetic fields with very low frequency and providing control strategy. 16nd national congress of envrionmental health; Tabriz, Iran,2013 [In Persian]

20. Abbasi M, Monazzam MR, Akbarzadeh A, Zakerian SA, Ebrahimi MH. Impact of Wind Turbine Sound on General Health, Sleep Disturbance and Annoyance of Workers: A pilot-study in Manjil Wind Farm, Iran. J Environ Health Sci Eng 2015;13(1):71.

21. Neghab M, Kardaneyan M, Norozi MA. Health Effects Associated with Occupational Exposure to Low Levels of Mercury Vapors by Employees of a Chloralkali Plant. Iran Occup Health J 2010;7(1):0-4 [In Persian].

22. Nabipoor E. The Guidance of Health Impact Assessment in Oil and Gas Industry. Boushehr2012. 156 p. Available from:

http://pgtmrc.bpums.ac.ir/UploadedFiles/xfiles/HIA.pdf [In Persian].

23. Gharchloo J, Mobarghaei N, Niknam M. Assessment, Planning and Analysis of Advers Environmental Effect of Development Petrochemical Industries in Iran by Emphasis on Health Risk Assessment. 1nd national conference of city architecture, construction and environment; Hamedan 2014. http://www.civilica.com/ Paper-ARCHITECTURE01ARCHITECTURE01 218.html [In Persian].
24. Sadr MK, Nassiri P, Hosseini M, et al. Assessment of Land Use Compatibility and Noise Pollution at Imam Khomeini International Airport. J Air Transport Manage 2014;34:49-56

25. Geravandi S, Takdastan A, Zallaghi E, et al. Noise Pollution and Health Effects. Jundishapur J Health Sci 2015;7(1). DOI: 10.5812/jjhs.25357.

26. Bahrainy $\mathrm{H}$, Khosravi $\mathrm{H}$. The Impact of Urban Design Features and Qualities on Walkability and Health in Under-Construction Environments: The Case of Hashtgerd New Town in Iran. Cities. 2013;31:1728.Available from: http://dx.doi.org/10.1016/j.cities.2013.01.001.

27. Keshavarzi B, Tazarvi Z, Rajabzadeh MA, Najmeddin A. Chemical Speciation, Human Health Risk Assessment and Pollution Level of Selected Heavy Metals in Urban Street Dust of Shiraz, Iran. Atmos Environ J 2015;119:110.DOI: 10.1016/j.atmosenv.2015.08.001.

28. Khorasani-Zavareh D, Mohammadi R, Khankeh HR, Laflamme L, Bikmoradi A, Haglund BJ. The Requirements and Challenges in Preventing of Road Traffic Injury in Iran. A Qualitative study. BMC Public Health J 2009;9(1):486.

29. Mahdi A, Hosseini A, Pourahmad A, Hataminejad H. Analysis of Effective Environmental Factors an Urban Health, A Case Study of Qom, Iran. Habitat Int J 2016;55:89-99. http://dx.doi.org/10.1016/j.habitatint.2016.03.001.

30. Nadrian H, Nedjat S, Taghdisi MH, Shojaeizadeh D. Urban Traffic-Related Determinants of Health Questionnaire (UTDHQ): An Instrument Developed for Health Impact Assessments. Med J IRI 2014;28:84.

31. Sodagari M, Salehi A. Application Evaluation of Health Impact Assessment in City Construction Project. 2nd conference on environmental plannig and management; 15-16 MAY 2012; Tehran2012 Available from: http://www.civilica.com/Paper-ESPME02ESPME02_319.html [In Persian]

32. Shojaei P. Impact Assessment of Construction Artificial lake in City Developmenet Programs on Health and their Social Determinants 2014. Available from: http://www.virascience.com/thesis/811326/[In Persian].

33. Shojaei P, Setareforouzan A. Health Impact Assessment of Transportation Program. 11nd international conference of transportation and traffic engineering. Available from: http://www.wikipg.com/images/context/files/matalebe $\% 2$ 0elmi/maghalate\%20omran/102.pdf [In Persian].

34. Shojaei P, Karimlou M, Nouri J, Mohammadi F, Afzali HM, Forouzan AS. Ranking the effects of urban development projects on social determinants of health: health impact assessment. Global J Health Sci 2014;6(5):183. 


$$
\text { مرور سيستماتيك بر روى بررسى جايكاه ارزيابى اثرات بر سلامت در ايران: تكامل، تحقيقات و زمينهایى بهبود آن }
$$

35. Farzadfar F, Danaei G, Namdaritabar H, et al. National and Subnational Mortality Effects of Metabolic Risk Factors and Smoking in Iran: A Comparative Risk Assessment. Popul health metrics. 2011;9(1):55.

36. Djalalinia S, Qorbani M, Peykari N, Kelishadi R. Health Impacts of Obesity. Pakistan J Med Sci 2015;31(1):239.

37. Mozaffarian D, Abdollahi M, Campos H, Houshiarrad A, Willett W. Consumption of Trans fats and Estimated Effects on Coronary Heart Disease in Iran. Eur J Clin Nutr 2007;61(8):1004-10.

38. Fakhri A, Maleki MR. A Pattern for Health Impact Assessment of Development Plants in Iran. Hakim Health Syst Res J 2015;18(1):83-9 [In Persian].

39. Fakhri A, Maleki M, Gohari M, Harris P. Investigating Underlying Principles to Guide Health Impact Assessment. Int J Health Policy Manage 2014;3(1):17-22.

40. Yazdizadeh B, Majdzadeh R, Janani L, et al. An Assessment of Health Research Impact in Iran. Health Res Policy Syst 2016;14(1):56.

41. Zare H, Trujillo AJ, Driessen J, et al. Health Inequalities and Development Plans in Iran; An Analysis of the Past three Decades (1984-2010). Int J Equity Health 2014;13(1):42.

42. Mosaferi M BA, Taghipoor N. Health Impact Assessment(HIA) The New Approach in Impact Assessment of Development Plants in Iran. the 16nd national congress of environmental health. Azarbaijanesharghi2013. Available from: http://congress.tbzmed.ac.ir/BE/pdf/be_13728.pdf [In Persian].

43. Fatemi F. Health Impact Assessment, Concepts,Steps and Applications. the 2nd conference on environmental planning and management; 15-116 MAY 2012; Tehran2012. http://www.civilica.com/Paper-ESPME02ESPME02_242.html [In Persian].

44. Rezaei Kalantari R, Farzadkia M. Development Impact Assessment on Environmental Health. Iran Occup Health 2010;6(4):4-6[In Persian].

45. Ghaffarzadeh N, Bagheri M. review of health impact assessment, structural framework and types. 12nd national congress of environmental health; Tehran2009. http://www.civilica.com/Paper-NCEH12NCEH12_202.html [In Persian].

46. Shojaei P, Malekafzali H, Karimloo M, et al. Review of Health Impact Assessment Models. Refah J 2012;12(47):7-28 [In Persian].

47.Fakhri A, Harris P, Maleki M. Lessons learnt from developing a Health Impact Assessment guide in Iran. J Public Health Policy 2016:1-13.

48. Aslehashemi A, Dowlatkhah M. Health and Environmental Impact of Hazardous Chemical Material. 1nd professional congress of environmental engineering;
Tehran2006. http://www.civilica.com/Paper-CEE01CEE01_039.html [In Persian].

49. Environmental Impact Assessment Instruction of Water and Wastewater Plans in Detailed Phase, Publication NO. 338. 2006. Available from:

http://waterstandard.wrm.ir/uploaded_files/DCMS/WRMRes earch_files/338-S.pdf[In Persian].

50. Yunesian M, Dastoorani M, Noori J,et al. Environmental Health Impact Assessment of Construction Industrial Park. J School Health 2009;7(1):1-9 [In Persian].

51. Dehghanifard E, Asgari A ,Lleili M, Dehghanifard S. Evaluation of Health and Environmental Effects of Radioactive Material: Case Study of Depleted Uranium. 1nd conference of transportation of hazardous material and their environmental effects; Tehran2008. http://www.civilica.com/Paper-HAZMAT01HAZMAT01_014.html [In Persian].

52. Health Impact Assessment Report of Park Banovan and Kaspian Industry Park Projects. Ghazvin2011.Available from: http://eprints.qums.ac.ir/3521/1/kaspiyan.pdf [In Persian].

53. Mousavi B, Soroush MR, Montazeri A. Quality of Life in Chemical Warfare Survivors with Ophthalmologic Injuries: The First Results form Iran Chemical Warfare Victims Health Assessment Study. Health and Quality of life outcomes. 2009;7(1):2.

54. Slami H, Alifallahzadeh R, Khosravi R, Sodagari M. Framework of Health Impact Assessment for Vulnerability Assessment Due to Climate Change. 1nd national congress of natural environmental2015. http://www.civilica.com/Paper-NECONF01NECONF01_114.html [In Persian].

55. Health Impact Assessment, Nutrition Values and Usefulness of Domestic Water Desalination Devices in Qom City 2009. Available from: http://www.abfaqom.com/node/2487 [In Persian].

56. Sodagar H, Rezaei H, Motahari A. Health Impact Assessment and Role of It in Siting Waste Disposal Place. 3nd conference environmental science, engineering and technologies2016. Available from: https://ceset.ut.ac.ir/paper?manu=23031[In Persian].

57. Asadi A, Poormoghaddas H. Health and Environmental Impact Assessment of Dioxin and Related Compounds. 1nd national congress of environment, occupation and cancer in iran; tehran2006.Available from: http://health.barakatkns.com/seminar-article/306776/[In Persian].

58. Ghozikali M, Borgini A, Tittarelli A, et al. Quantification of Health Effects of Exposure to Air Pollution (PM10) in Tabriz, Iran. Glob Nest J 2016;18(4):708-20.

59. Ammarloee A, Jonidi Jafar iA, Asilianmahabadi $H$, Asadollahi K. Estimation of Health Impact Related to PM10 Due to Dust Storm in Ilam City2012-2013. Scientific J Kurdistan U Med Sci 2015;20: 21-61 [In Persian].

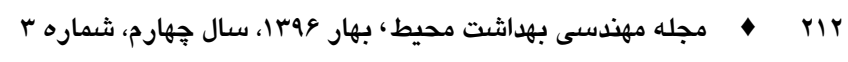




$$
\text { ادريس حسين زاده و همكاران }
$$

60. Kermani M, Aghaei M, Gholami M ,et al. Estimation of Mortality Attributed to PM2.5 and CO Exposure in eight Industrialized Cities of Iran During 2011. Iran Occup Health J 2016;13(4):49-61 [In Persian].

61. Gharehchahi E, Mahvi AH, Amini H,et al. Health Impact Assessment of Air Pollution in Shiraz, Iran: A two-part Study. J Environ Health Sci Eng 2013;11(1):11.

62. Amiri H, Noorisepehr M, Hasanvand MS, Mazloomi S. Health Impact Assessment (Mortality and Morbidity Due to Cardiovascular and Respiratory Disease) Related to PM2.5 and $\mathrm{O} 3$ in Air of Karaj City. 16nd national congress of environmental health; tabriz2013. http://www.civilica.com/paper-NCEH16NCEH16_061.html [In Persian].

63. Mokhtari M, Miri M, Mohammadi A,et al. Assessment of Air Quality Index and Health Impact of PM10, PM2. 5 and SO2 in Yazd, Iran. J Mazandaran U Med Sci 2015; 25(131): 14-23.

64. Bonyadi Z, Ehrampoush MH, Ghaneian MT. Health Impact Assessment of the Ambient PM2.5 Concentration in Mashhad, Iran, in 2013. J Rafsanjan U Med Sci 2016;15(5):389-98 [In Persian].

65. Miri M, Derakhshan Z, Allahabadi A, et al. Mortality and Morbidity Due to Exposure to Outdoor Air Pollution in Mashhad Metropolis, Iran. The AirQ Model Approach. Environ Res 2016;151:451-7.

66. Khaniabadi YO, Hopke PK, Goudarzi G, et al.Cardiopulmonary Mortality and COPD Attributed to Ambient Ozone. Environ Res 2017;152:336-41.

67. Dehghanifard E, Alireza A, Ghanbari R. Air Pollutants Due to Depleted Uranium Applications and their Environmental Impacts. 1nd professional congress of environmental engineering; Tehran2006. http://www.civilica.com/paper-CEE01-CEE01_392.html [In Persian].

68. Arfaeinia H, Moradi M, Sharafi K, et al. Evaluation of Public Health Impacts Related To Urban Air Pollution In Shiraz And Bushehr, Iran. Int J Pharm Tech 2015;7(3):9811-24.

69. Kermani M, Dowlati M, Jonidi Jafari A, Rezaei Kalantari R. Estimation of Mortality, Acute Myocardial Infarction and Chronic Obstructive Pulmonary Disease due to Exposure to $\mathrm{O} 3, \mathrm{NO} 2$, and $\mathrm{SO} 2$ in Ambient Air in Tehran. J Mazandaran U Med Sci 2016;26(138):96-107.

70. Kermani M, Dowlati M, Jonidi Jafari A,et al. Effect of Air Pollution on the Emergency Admissions of Cardiovascular and Respiratory Patients, Using the Air Quality Model: A Study in Tehran, 2005-2014. Health Emerg Disasters Quart 2016;1(3):137-46.

71. Fallah Jokandan S. Estimation of Cardiovascular Death, Myocardial Infarction and Chronic Obstructive Pulmonary Disease (COPD) Attributed to SO2 Exposure in six Industrialized Metropolises of Iran. Razi J Med Sci 2016; 23(145):12-21 [In Persian].
72. Maleki H, Sorooshian A, Goudarzi G, Nikfal A, Baneshi MM. Temporal Profile of PM10 and Associated Health Effects in one of the Most Polluted Cities of the World (Ahvaz, Iran) Between 2009 and 2014. Aeolian Res 2016;22:135-40.

73. Mohammadi MJ, Godini H, Tobeh Khak MT,et al. An Association Between Air Quality and COPD in Ahvaz, Iran. Jundishapur J Chronic Dis Care 2015;4(1). DOI: $10.5812 /$ jjcdc. 26621.

74. Naddafi K, Hassanvand MS, Yunesian M, et al. Health Impact Assessment of Air Pollution in Megacity of Tehran, Iran. J Environ Health Sci Eng 2012;9(1):28.

75. Hosseinpoor AR, Forouzanfar MH, Yunesian M, et al. Air Pollution and Hospitalization Due to Angina Pectoris in Tehran, Iran: A time-series study. Environ Res 2005;99(1):126-31.

76. Nourmoradi H, Goudarzi G, Daryanoosh SM, OmidiKhaniabadi F. Health Impacts of Particulate Matter in Air using AirQ Model in Khorramabad City, Iran. J Basic Res Med Sci 2015;2(2):52-44.

77. Daryanoosh SM, Goudarzi G, Khaniabadi YO,et al. Effect of Exposure to PM10 on Cardiovascular Diseases Hospitalizations in Ahvaz, Khorramabad and Ilam, Iran During 2014. Iran J Health Safety Environ 2016;3(1):428-33.

78. Nourmoradi H, Khaniabadi YO, Goudarzi G,et al. Air Quality and Health Risks Associated with Exposure to Particulate Matter: A cross-sectional study in Khorramabad, Iran. Health Scope 2016;5(2). DOI: $10.17795 /$ jhealthscope-31766.

79. Gholampour A, Nabizadeh R, Naseri S,et al. Exposure and Health Impacts of Outdoor Particulate Matter in two Urban and Industrialized Area of Tabriz, Iran. J Environ Health Sci Eng. 2014;12(1):27.

80. Hosseini G, Maleki A, Amini $\mathrm{H}$, et al. Health Impact Assessment of Particulate Matter in Sanandaj, Kurdistan, Iran. J Adv Environ Health Res 2014;2(1):54-62.

81. Goudarzi G, Mohammadi M, Ahmadi Angali K, et al. Estimation of Number of Cardiovascular Death, Myocardial Infarction and Chronic Obstructive Pulmonary Disease (COPD) from NO2 Exposure using Air Q Model in Ahvaz City During 2009. Iran J Health Environ 2013;6(1):91-102 [In Persian].

82. Goudarzi G, Geravandi S, Saeedimehr S, et al. Estimation of Health Impact Due to Exposure to PM10 by AirQ Model in Ahvaz City2009. Iran J Health Environ. 2014;8(1):117-26 [In Persian].

83. Goudarzi G, Geravandi S, Mohammadi MJ, et al. The Relationship Between Air Pollution Exposure and Chronic Obstructive Pulmonary Disease in Ahvaz, Iran. Chronic Dis J 2015;3(1):14-20.

84. Zolghi E, Goudarzi G, Geravandi S, et al. Estimation of Cardiovascular and Respiratory Disease Related to PM10 in Air of Tabriz 2011. J Ilam U Med Sci 2014;22(1):8491 [In Persian]. 


\section{مرور سيستماتيك بر روى بررسى جايكاه ارزيابى اثرات بر سلامت در ايران: تكامل، تحقيقات و زمينهایى بهبود آن}

85. Goudarzi G, Geravandi S, Mohammadi MJ, et al. Total Number of Deaths and Respiratory Mortality Attributed to Particulate Matter (PM 10) in Ahvaz, Iran During 2009. Int J Environ Health Eng 2015;4(1):33.

86. Yari AR, Goudarzi G, Geravandi S, et al. Study of Ground-level Ozone and its Health Risk Assessment in Residents in Ahvaz City, Iran During 2013. Toxin Rev 2016;35(3-4):201-6.

87. Motalleby M, Mazaheri A, Mosayebi M, Takhtfiroozeh M. Assessing Health Impacts of Air Pollution in Kashan 2011. Arak Med U J 2015;18(5):77-87.

88. Noorbakhsh M, Ashrafipoor R, Yadollahi A, Ghanbari N. Health Impact Assessment of Exposure to $\mathrm{O} 3$ and $\mathrm{SO} 2$ in Sari Squares. 2nd professional congress of environment engineering2008. http://www.civilica.com/Paper-CEE02CEE02_476.html. [In Persian].

89. Noorbakhsh M, Rokni M, Mahmoudirad H, Ghanbari N. Health Impact Assessment of Ambient Dust in Imam Square of Sari by Standard Clean Air Index and AQI. 6nd national congress of environmental engiennring 2012. CEE06_445.html.[In Persian].

90. Bonyadi Z, Ehrampoush MH, Ghaneian MT,et al. Cardiovascular, Respiratory, and Total Mortality Attributed to PM2. 5 in Mashhad, Iran. Environ Monit Asses 2016; 188(10): 570 .

91. Amini H, Taghavi-Shahri S-M, Henderson SB,et al. Annual and Seasonal Spatial Models for Nitrogen Oxides in Tehran, Iran. Sci Reports 2016;6. DOI: 10.1038/srep32970.

92. Zallaghi E, Goudarzi G, Haddad MN,et al. Assessing theEffects of Nitrogen Dioxide in Urban Air on Health of
West and Southwest Cities of Iran. Jundishapur J Health Sci 2014;6(4). DOI: 10.5812/jjhs.23469.

93. Aliakbari K. Estimation of Health Impact of Air Pollution of Tehran by AirQ Model in 2011. 2011. Available from: http://dsp.sbmu.ac.ir/handle/123456789 $\quad / 46361$. [In Persian].

94.Goudarzi G, Daryanoosh S, Godini H, Hopke P, Sicard P, De Marco A, et al. Health risk assessment of exposure to the Middle-Eastern Dust storms in the Iranian megacity of Kermanshah. J Pub Health 2017;148:109-16.

95.Kermani M, Dowlati M, Jonidi Jafari A, Rezaei Kalantari R. Health impact caused by exposure to particulate matter in the air of Tehran in the past decade. Tehran U Med Sci 2017;74(12):885-92.

96.Khaefi M, Geravandi S, Hassani G, Yari AR, Soltani F, Dobaradaran S, et al. Association of particulate matter impact on prevalence of chronic obstructive pulmonary disease in Ahvaz, southwest Iran during 2009-2013. Aerosol Air Qual Res 2017;17(1):230-7.

97.Tashayo B, Alimohammadi A, Sharif M. A Hybrid Fuzzy Inference System Based on Dispersion Model for Quantitative Environmental Health Impact Assessment of Urban Transportation Planning. Sustainability 2017;9(1):134.

98.Fard RF, Naddafi K, Yunesian M, Nodehi RN, Dehghani $\mathrm{MH}$, Hassanvand MS. The assessment of health impacts and external costs of natural gas-fired power plant of Qom. Environ Sci Pollut Res 2016; 23(20): 20922-36.

99. Miri M, Aval HE, Ehrampoush MH, Mohammadi A, Toolabi A, Nikonahad A, et al. Human health impact assessment of exposure to particulate matter: an AirQ software modeling. Environ Sci Pollut Res 2017;24(19): 16513-16519. 